Article

\title{
Thermophysical Features of the Rümker Region in Northern Oceanus Procellarum: Insights from CE-2 CELMS Data
}

\author{
Zhiguo Meng ${ }^{1,2,3, *(\mathbb{C}}$, Jietao Lei $\left.{ }^{1}{ }^{(}\right)$, Yuqi Qian ${ }^{4,5}{ }^{(}$, Long Xiao ${ }^{4}$, James W. Head ${ }^{5}$, \\ Shengbo Chen ${ }^{1}$, Weiming Cheng ${ }^{2} \mathbb{D}$, Jiancheng Shi ${ }^{6}{ }^{\circ}$, Jinsong Ping ${ }^{7}$ and Zhizhong Kang ${ }^{8,9} \mathbb{C}$ \\ 1 College of Geoexploration Science and Technology, Jilin University, Changchun 130026, China; \\ leijt19@mails.jlu.edu.cn (J.L.); chensb@jlu.edu.cn (S.C.) \\ 2 State Key Laboratory of Resources and Environmental Information System, Institute of Geographic Sciences \\ and Natural Resources Research, Chinese Academy of Sciences, Beijing 100101, China; chengwm@lreis.ac.cn \\ 3 Institute of National Development and Security Studies, Jilin University, Changchun 130026, China \\ 4 School of Earth Sciences, China University of Geosciences, Wuhan 430074, China; \\ yuqi_qian@cug.edu.cn (Y.Q.); longxiao@cug.edu.cn (L.X.) \\ 5 Departmental of Earth, Environmental, and Planetary Sciences, Brown University, \\ Providence, RI 02912, USA; James_Head@brown.edu \\ 6 National Space Science Center, Chinese Academy of Sciences, Beijing 100012, China; shijiancheng@nssc.ac.cn \\ 7 Key Laboratory of Lunar and Deep Space Exploration, National Astronomical Observatory, \\ Chinese Academy of Sciences, Beijing 100012, China; jsping@bao.ac.cn \\ 8 School of Land Science and Technology, China University of Geosciences, Beijing 100083, China; \\ zzkang@cugb.edu.cn \\ 9 Subcenter of International Cooperation and Research on Lunar and Planetary Exploration, Center of Space \\ Exploration, Ministry of Education of the People's Republic of China, Beijing 100083, China \\ * Correspondence: mengzg@jlu.edu.cn; Tel.: +86-186-4306-2191
}

Received: 5 September 2020; Accepted: 6 October 2020; Published: 8 October 2020

\begin{abstract}
The Rümker region is located in the northern Oceanus Procellarum, which has been selected as the landing and sampling region for China's Chang'e-5 (CE-5) mission. The thermophysical features of the mare units are studied in detail using the brightness temperature (TB) maps (TB, normalized TB, TB difference) derived from the CE-2 microwave radiometer data. The previously interpreted geological boundaries of the Rümker region are revisited in this study according to their TB behaviors: IR1, IR2, and IR3 Rümker plateau units are combined into one single unit (IR); and a hidden unit is found on the Mons Rümker; Mare basaltic units Im1 and Em1 are combined into Em1; and Em2 is more likely the extending of Im2. Each of the previous proposed landing sites and their scientific value are summarized and reevaluated. Based on this, four landing sites are recommended in order to maximize the scientific outcome of the CE- 5 mission. We suggest that the Eratosthenian-aged Em4 and Em1 units as the top priority landing site for the CE-5 mission; the age-dating results will provide important clues concerning the thermal evolution of the Moon.
\end{abstract}

Keywords: the Rümker region; thermophysical features; CELMS data; Chang'e-5 mission; mare volcanism; lunar landing site

\section{Introduction}

The Chang'e-5 (CE-5) mission, scheduled to launch at the end of 2020, is China's first lunar sample return mission [1-3]. The Rümker region $\left(41-45^{\circ} \mathrm{N}, 49-69^{\circ} \mathrm{W}\right.$; Figure 1a) in northern Oceanus Procellarum has been selected as the landing region [4]. 


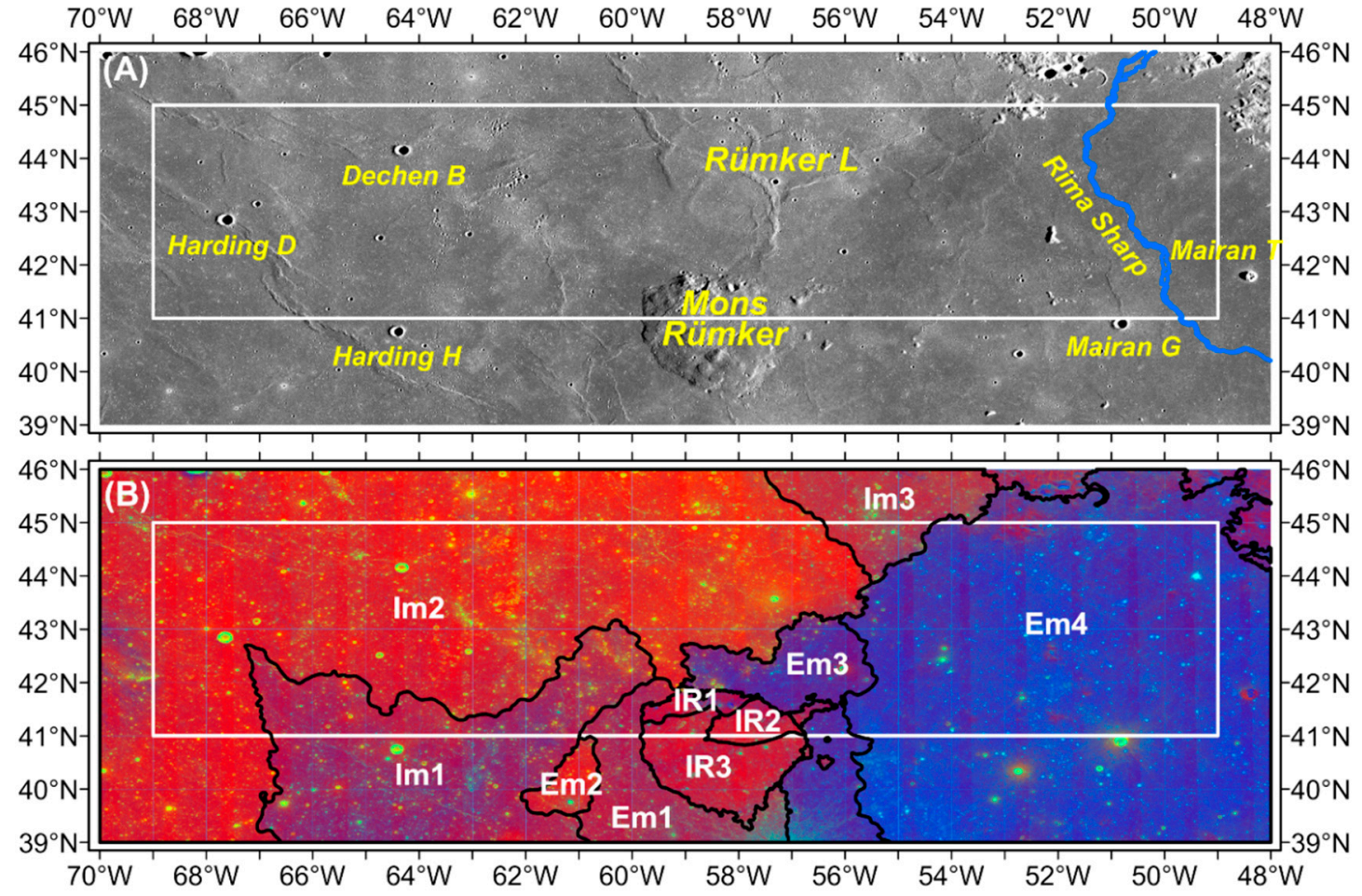

Figure 1. (A) CE-5 landing region in northern Oceanus Procellarum. Mons Rümker is a huge volcanic complex in the south of the CE-5 landing region. The basemap is a Kaguya TC Morning Map. (B) The geological units are summarized by Qian et al. [2]. IR1, IR2, and IR3 are Rümker plateau units; Im1, $\operatorname{Im} 2$, and Im3 are Imbrian-aged low-Ti mare basalts; Em1, Em2, Em3, and Em4 are Eratosthenian-aged high-Ti mare basalts.

The CE-5 landing region is located in the northwest part of the Procellarum KREEP Terrane (PKT), far from the previous Apollo and Luna landing sites. PKT is one of the three most prominent geochemical anomalies on the Moon (i.e., Procellarum KREEP Terrane, Feldspathic Highlands Terrane, and South Pole-Aitken Terrane; Jolliff et al. [5]). It underwent a complex geological history, including multiple volcanic episodes with different element composition and mineral assemblages, and is described as the most interesting place for recent and future missions to understand some of the most fundamental scientific questions of selenology, such as the properties of late stage lunar volcanism and the deep mantle materials [6,7]. The elevated levels of heat-producing elements [8] and thin crust (usually $<30 \mathrm{~km}$, Wieczorek et al. [9]), may serve to enhance the generation, ascent, and eruptions of lunar basaltic magma $[10,11]$, which could be the factor leading to an extended period of volcanism in the region [12,13], producing the most recent mare basalts (about $1.21 \mathrm{Ga}$ ) on the Moon [14-16]. Within the PKT, the Rümker region displays a spectrum of lunar volcanism and related products [2], from basaltic mare eruptions to silica-rich dome eruptions [17], from Imbrian-aged mare flows to Eratosthenian-aged mare flows, from long-term construction of a huge volcanic complex (i.e., Mons Rümker; Zhao et al. [1]) to short-term eruption [18] of the longest sinuous rille on the Moon (i.e., Rima Sharp), etc. On the basis of the distribution of different kinds of volcanic products, especially some of the youngest mare basalts on the Moon [2], the Rümker region has been chosen as the candidate sampling region for the Chang'e-5 mission [4]. Samples from the region could profoundly improve our understandings of lunar impact and thermal history [2].

The geological history of the Rümker region and northern Oceanus Procellarum has been fully studied with spectral data. Based on mineralogical and geochemical characteristics and impact populations, Zhao et al. [1] and Qian et al. [2] mapped three Rümker plateau units (i.e., IR1, IR2, and IR3; basaltic in composition) and seven mare basaltic units (Figure 1b). The mare basalts are subdivided into three Imbrian-aged units (Im1, Im2, and $\operatorname{Im} 3$ ), characterized by low-Ti, low-Fe 
contents, and a high crater density [2]; and four Eratosthenian-aged units (Em1, Em2, Em3, and Em4), characterized by high-Ti, high-Fe, and high-Th contents, richer in olivine than the old Imbrian-aged mare basalts on the eastern nearside, and a lower crater density [2]. Although the crater size-frequency distribution (CSFD) absolute model ages of each geological unit may be more complicated [19-22], the subdivisions of geological units are diagnostic in terms of surface reflectance data and derived compositional data (e.g., Clementine UVVIS data and Kaguya MI data) and correspond well with Hiesinger et al. [14,16] and Boroughs and Spudis [23], etc.; therefore, we mainly assess and address their results in this study.

CE-5 plans to collect $\sim 2 \mathrm{~kg}$ ( $\sim 2 \mathrm{~m}$ in core length) of lunar regolith from the surface utilizing a robotic arm and subsurface drilling [24], to study the subsurface structures, especially regolith properties. However, until now, the geological study of the Rümker region is mainly based on spectral and topographic data $[2,20,22]$, and details of the regolith properties of the CE-5 landing region are not well constrained. Campbell et al. [25] analyzed the surface properties of Mons Rümker with Earth-based radar data and found it likely to be covered with rock-poor, fine-grained pyroclastic materials. Xie et al. [26] quantitatively estimated the abundance variations of distantly sourced particles with depth using an updated ballistic sedimentation model, concluding that most of the extraneous materials are derived from Pythagoras ( $\sim 5 \%)$ and Aristarchus craters ( 7\%). Qian et al. [27] and Yue et al. [28] studied the regolith thickness of the region, and found that the Imbrian-aged mare basalts have thicker regolith than the Eratosthenian-aged and that over $99 \%$ of the Rümker region has a regolith thickness larger than $2 \mathrm{~m}$ (the length of the core drill). Chisenga et al. [29] applied a 3D density inversion to resolve both the shallow and deep density structures using Gravity Recovery and Interior Laboratory (GRAIL) data; they proposed that Mons Rümker is fed by a shallow magma chamber and a quasi-circular gravity anomaly may be the source region of the Eratosthenain-aged mare basalts in the Rümker region. All in all, an improved understanding of the regolith, its subsurface properties, and thermophysical features are of great interest due to the importance for mission operations and drilling, and the great scientific value of the mission.

The global brightness temperature (TB) of the Moon was first measured by a microwave radiometer (CELMS) onboard China's Chang'e-1 (CE-1) and Chang'e-2 (CE-2) spacecraft, operating at 3.0 GHz, 7.8 GHz, $19.35 \mathrm{GHz}$, and $37.0 \mathrm{GHz}$ channels. The penetration depth of CELMS is about $1 \mathrm{~m}$ at $3.0 \mathrm{GHz}$, $38.5 \mathrm{~cm}$ at $7.8 \mathrm{GHz}, 15.5 \mathrm{~cm}$ at $19.35 \mathrm{GHz}$, and $8.1 \mathrm{~cm}$ at $37 \mathrm{GHz}$ [25,30,31], owing to the high iron and titanium abundances of the Rümker region [2]. The CELMS data is sensitive to the chemical components and temperature of the substrate regolith [30,32-35], providing an opportunity to unravel its structures. In this case, the CE-2 CELMS data are employed to evaluate the thermophysical features of the basaltic units in the Rümker region, in order to better understand the basaltic volcanism of the region and provide additional supports for the CE-5 mission.

\section{Brightness Temperature}

The Brightness Temperature (TB) of the lunar regolith at different microwave frequencies and its characteristics have been well investigated theoretically by a number of authors [36,37] and are widely used to obtain global lunar heat flow and average regolith thickness [38]. The thermophysical features of TB could provide a more reliable estimation of the substrate structures that are less influenced by lateral mixing of materials that may contaminate optical measurements [39-41].

To better understand the findings in this study, the radiative transfer theory is used to model the TB from the regolith. The mare deposit is thought as two layers, including a regolith layer and a rock layer $[30,38,41]$. Then, TB is modeled by the radiation from the regolith layer and the rock layer. Considering a $0^{\circ}$ observation angle of CELMS instrument, the radiative transfer simulation is expressed as follows: 


$$
\begin{aligned}
& T B=\int_{0}^{d} \frac{1-r_{1}}{1-L} k_{a 1}(z) T(z)_{1} \mathrm{e}^{-\int_{0}^{z} k_{a 1}\left(z^{\prime}\right) \mathrm{d} z^{\prime}} \mathrm{d} z+\int_{0}^{d} \frac{\left(1-r_{1}\right) r_{2}}{1-L} k_{a 1}(z) T(z) \mathrm{e}^{-\left(\int_{z}^{d} k_{a 1}\left(z^{\prime}\right) \mathrm{d} z^{\prime}+\int_{0}^{d} k_{a 1}\left(z^{\prime}\right) \mathrm{d} z^{\prime}\right)} \mathrm{d} z \\
&+\int_{d}^{\infty} \frac{\left(1-r_{1}\right)\left(1-r_{2}\right)}{1-L} k_{a 2}(z) T(z) \mathrm{e}^{-\int_{d}^{z} k_{a 2}\left(z^{\prime}\right) \mathrm{d} z^{\prime}} \mathrm{d} z \cdot \mathrm{e}^{-\int_{0}^{d} k_{a 1}\left(z^{\prime}\right) \mathrm{d} z^{\prime}}
\end{aligned}
$$

where the first and second parts represent the upwelling and downwelling radiations of the regolith layer, and the third parts is the radiation from the rock layer. $\mathrm{d}$ is the regolith layer thickness; $k_{a 1}$ and $k_{a 2}$ are the absorption coefficients in the lunar regolith and rock layers, respectively; $T(z)$ is the temperature profile, which is obtained with a thermal conduction model [34]; $r_{1}$ and $r_{2}$ represent the effective reflectivity values of the free space-regolith and regolith-rock interfaces, respectively; and $1 /(1-L)$ is the multi-reflection coefficient.

The dielectric constant is a decisive factor for the parameters including $r_{1}, r_{2}, k_{a 1}$, and $k_{a 2}[39,40,42]$. Based on experiments on the lunar regolith samples, Heiken et al. [43] assessed the relationship between the real part of the relative dielectric constant $\varepsilon^{\prime}$, the loss tangent tan $\delta$, and the $\left(\mathrm{FeO}+\mathrm{TiO}_{2}\right)$ abundance (FTA) value $\mathrm{S}(\mathrm{wt} \%)$, which is expressed as follows:

$$
\left\{\begin{array}{l}
\varepsilon^{\prime}=1.919^{\rho} \\
\tan \delta=10^{0.038 S+0.312 \rho-3.260}
\end{array}\right.
$$

where $\rho$ is the density of the lunar regolith.

The relationship between TB and the thermophysical parameters of the lunar regolith can, then, be constructed by integrating Equation (1) over the total thickness d. Meng et al. [30,44] proposed that the regolith thickness $d$ plays a weak role on the TB. Thus, the regolith is assumed to be a 6-m-thick layer with a smooth surface. $T(z)$ is calculated with the thermal conductivity model and the innermost depth temperature is assumed to be $252 \mathrm{~K}$ [37] as a constraint to solve the model. The hyperbolic model is used to obtain the density parameter $\rho$. The dielectric constant of the rock layer is assumed to be $6.15+\mathrm{i} 0.155$ (the dielectric constant of sample No.1555 from the Apollo 15 mission, Heiken et al. [43]). Assuming a surface temperatures of $390 \mathrm{~K}$ (noon) and $100 \mathrm{~K}$ (night), the relationship between TB and FTA at noon and night can be simulated with Equations (1) and (2), as shown in Figure 2 for the 3.0 and $37 \mathrm{GHz}$ channels.

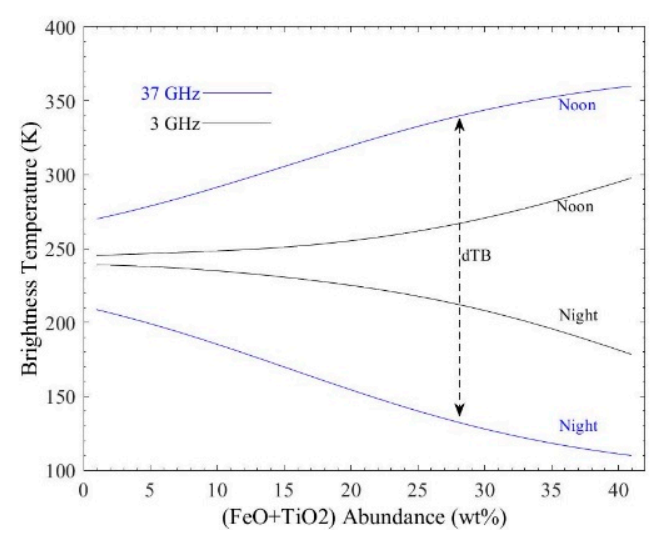

Figure 2. The relation between simulated TB with FTA at noon and night.

In this study, the difference between the noon $\mathrm{TB}$ and night $\mathrm{TB}$ of the same frequency is defined as dTB. Here, two observations should be noticed: (1) As the FTA increase from $1 \mathrm{wt} . \%$ to $41 \mathrm{wt} . \%$, the TB will monotonously increase at noon but decrease at night. This relationship will be used to re-evaluate the thermophysical features of the geological units of Qian et al. [2] (Section 4). (2) The mare deposits with higher FTA should have a higher TB at noon but a lower TB at night. The TB performances in 
the Imbrian-aged and Eratosthenian-aged units all agree with this conclusion. However, the Rümker plateau unit and several other places do not follow this relationship (Section 4).

\section{Data Processing}

In this study, the TB maps are derived from data from the CELMS instrument onboard the CE-2 spacecraft; the surface temperature is derived from the LRO Diviner data [45] and the numerical simulation [46]; and the $\mathrm{FeO}$ and $\mathrm{TiO}_{2}$ abundances are derived from SELENE Multiband Imager (MI) data [47].

\subsection{TB Maps Generation}

The CELMS data used in this study were obtained from the CE-2 spacecraft, from October 2010 to June 2011, at an altitude of $\sim 100 \mathrm{~km}[35,48]$, with an observation angle of $0^{\circ}$. CELMS instrument has four frequency channels $(3.0,7.8,19.35$, and $37.0 \mathrm{GHz})$, and each channel can reflect the thermophysical features of the lunar regolith at a specific penetration depth [30-33,49]. The used CELMS data is in $2 \mathrm{C}$ level, which is the raw data after geometric correction and radiometric calibration $[33,35,48]$. The radiometric accuracy of the CELMS data is better than $1.0 \mathrm{~K}$ [35]. The data is available from Data Release and Information Service System of China's Lunar Exploration Program (http://moon.bao.ac.cn/).

The CELMS data processing has been described in detail by Chan et al. [50], Zheng et al. [35,49], and Meng et al. [30,33,51]. The same processing method is adopted in this study.

Firstly, 19,942 CELMS data points are selected according to the range of the Rümker region. Secondly, the time angle is introduced to ascribe the selected CELMS data points into 24 lunar hours, where the data points in one hour are approximated to experience similar illumination conditions. Thereafter, the scatter maps in the $24 \mathrm{~h}$ are plotted to choose the proper observation times, since the CELMS data points are not intensive enough to generate the TB maps at every hour. After comparison, the data points from 1 p.m. to 2 p.m. and 4 a.m. to 5 a.m. are chosen to generate the TB maps, representing the observations at noon and night, respectively. Finally, the linear interpolation method is used to generate the TB maps at 3.0, 7.8, 19.35, and $37.0 \mathrm{GHz}$ with a spatial resolution of $0.25^{\circ} \times 0.25^{\circ}$. This data pre-processing algorithm has been tested and works well in previously published papers $[30,32,33,44,51]$.

The original TB map of the mare basalts in the Rümker region at $37 \mathrm{GHz}$ is shown in Figure 3 . The Em4 unit in the southeastern part has high FTA values; correspondingly, the $37 \mathrm{GHz}$ TB of Em4 is high at noon but low at night. The Im2 unit in the northwestern part has low FTA values; and the $37 \mathrm{GHz}$ TB of Im2 is low at noon but high at night. Such TB behaviors agree with the simulation results by Meng et al. [30,42] and Hu et al. [52], indicating the reliability of the generated TB maps.

\subsection{Proper TB Maps Generation}

Though the TB maps produced agree well with the components of the lunar regolith (Figure 3), the correspondence between $\mathrm{TB}$ and the geological boundaries is unclear. Moreover, from $39^{\circ} \mathrm{N}$ to $46^{\circ} \mathrm{N}$, the TB variations are about $20 \mathrm{~K}$ along the latitude, no matter whether at noon or at night. The latitude-dependent $\mathrm{TB}$ variations are much larger than regolith composition-dependent variations ( $\sim 10 \mathrm{~K}$ at noon and $\sim 5 \mathrm{~K}$ at night along the same latitude), which should be eliminated to reveal the true signal of regolith properties.

In this study, the normalized TB (nTB), TB difference (dTB), and emissivity maps are applied to solve latitude-dependent TB variation issues [30,32,33,44,51]. Moreover, to better understand the TB performances, the geological units identified by Qian et al. [2] are vectorized and overlain on the following generated maps. 

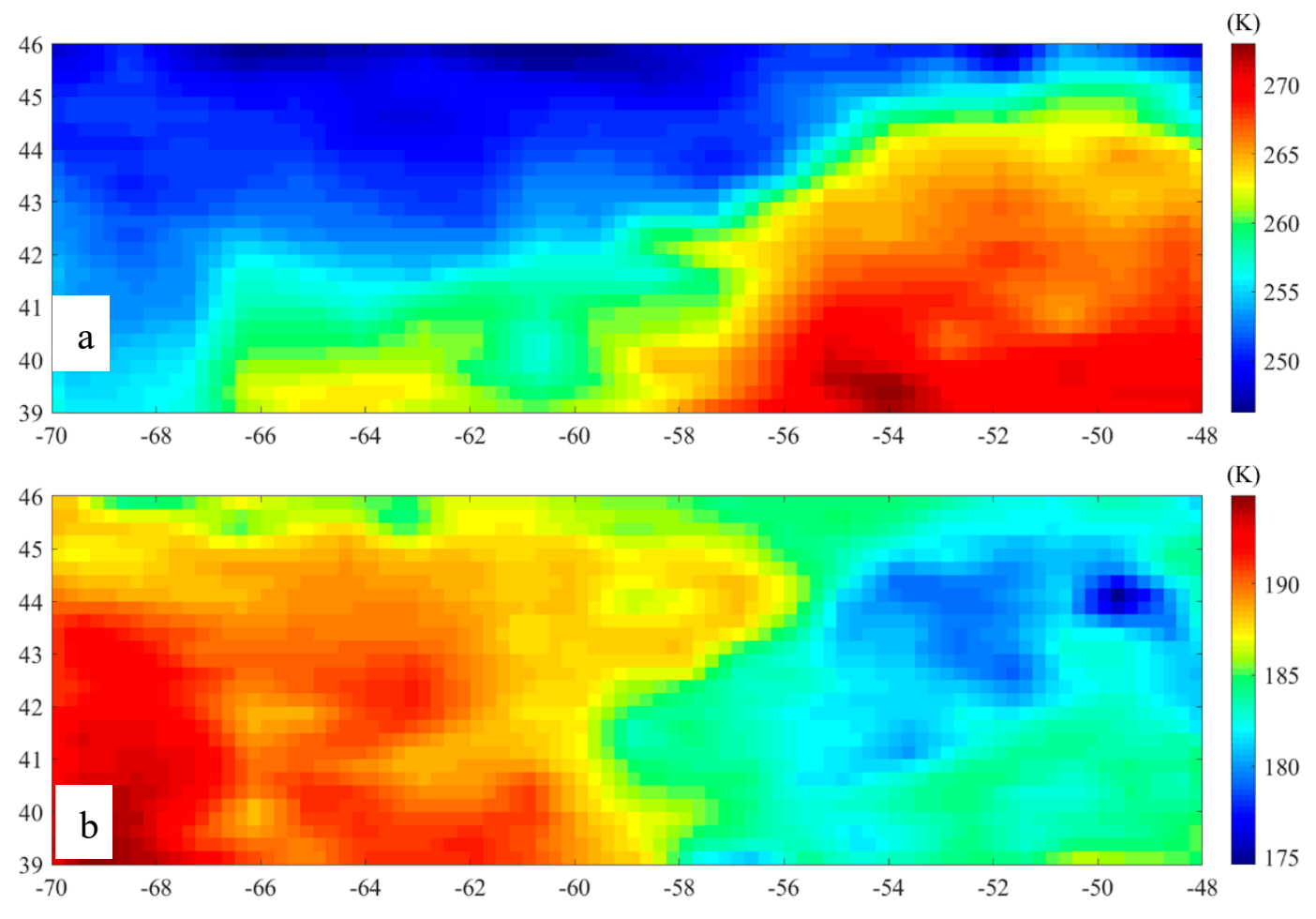

Figure 3. TB maps of the Rümker region at $37 \mathrm{GHz}$. (a) noon and (b) night.

\subsection{1. nTB Maps}

In order to obtain the nTB maps, the standard TB values of every latitude are calculated [32,33,51]. Firstly, one TB is selected for every latitude on the conditions that the FTA, surface slope, and rock abundance are similar in all selected positions (from the JMARS, https://jmars.asu.edu/). Then, a fitting curve is made according to the selected $\mathrm{TB}$, and the fitted value is defined as the standard TB for the corresponding frequency and latitude. Finally, the nTB maps are generated using the TB divided by the standard TB of the latitude (Figure 4, noon; Figure 5, night) [33,51].

Compared to the primary TB values (Figure 3), the latitude artifacts are considerably reduced, where the higher TB in the lower latitudes is weakened and the lower TB in higher latitudes is enhanced. This makes the nTB values of the same mare unit more homogeneous. Particularly in the $\operatorname{Im} 2$ unit, the nTB values are similarly low at noon and similarly high at night. A similar phenomenon also occurs in $\operatorname{Im} 1$ and Em4 units, indicating that the latitude-dependent effect of the TB maps is well resolved.

Generally, the nTB performances can be categorized into four grades. At noon, Em4 has the highest nTB values, followed by Em3, and Im 2 and Em2 have the lowest values. At night, Im 2 has the highest in nTB values, followed by $\operatorname{Im} 1, \operatorname{Im} 3$, and Em1, and Em4 has the lowest value. In addition, some abnormally high and low regions occur in the nTB maps (Figures 4 and 5), indicating the presence of inhomogeneous materials at depth, and will be discussed in detail later. 

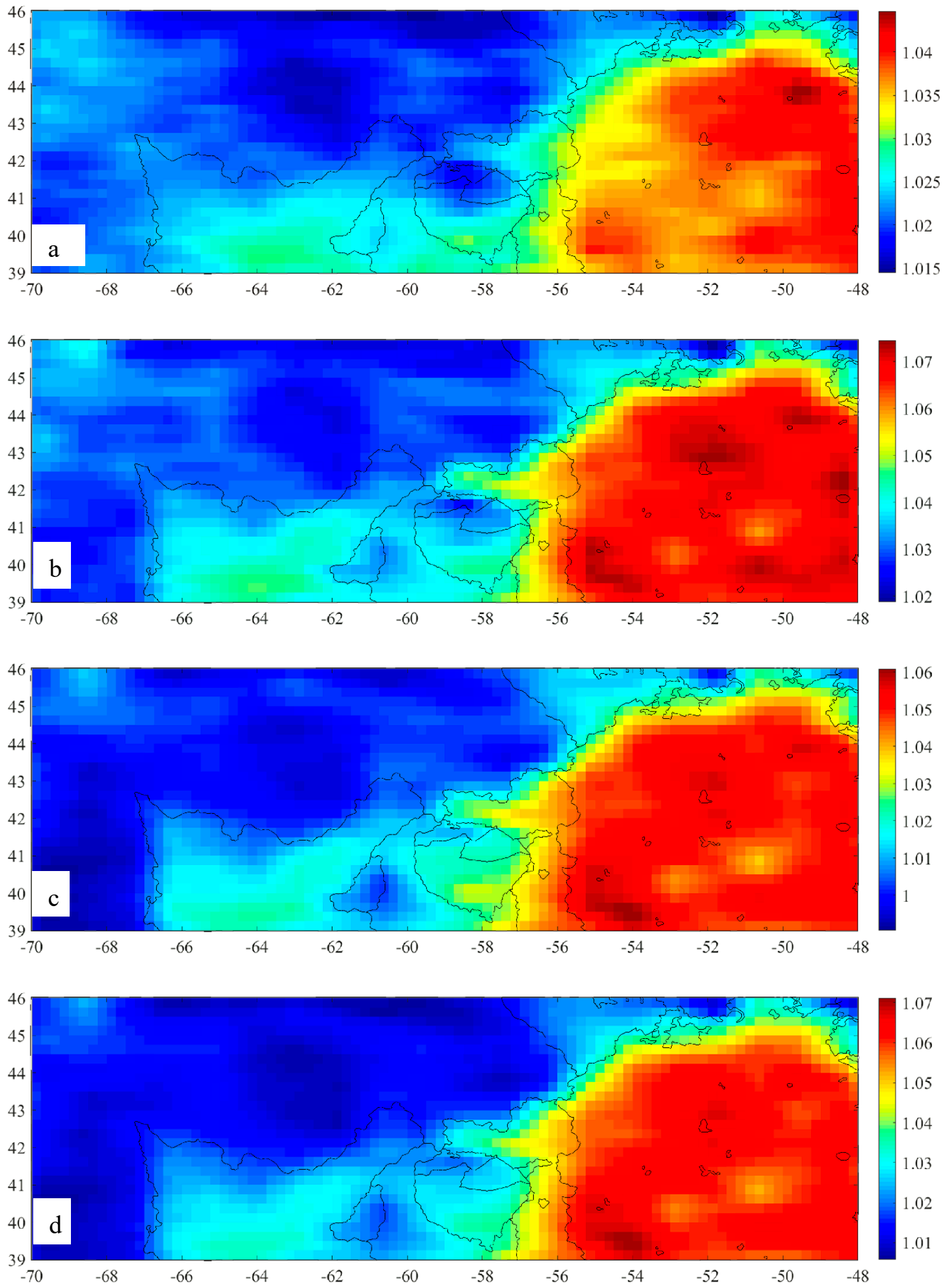

Figure 4. Normalized TB maps at noon: (a) $3.0 \mathrm{GHz}$, (b) $7.8 \mathrm{GHz}$, (c) $19.35 \mathrm{GHz}$, and (d) $37.0 \mathrm{GHz}$. The black lines denote the geologic boundaries of Qian et al. [2]. 

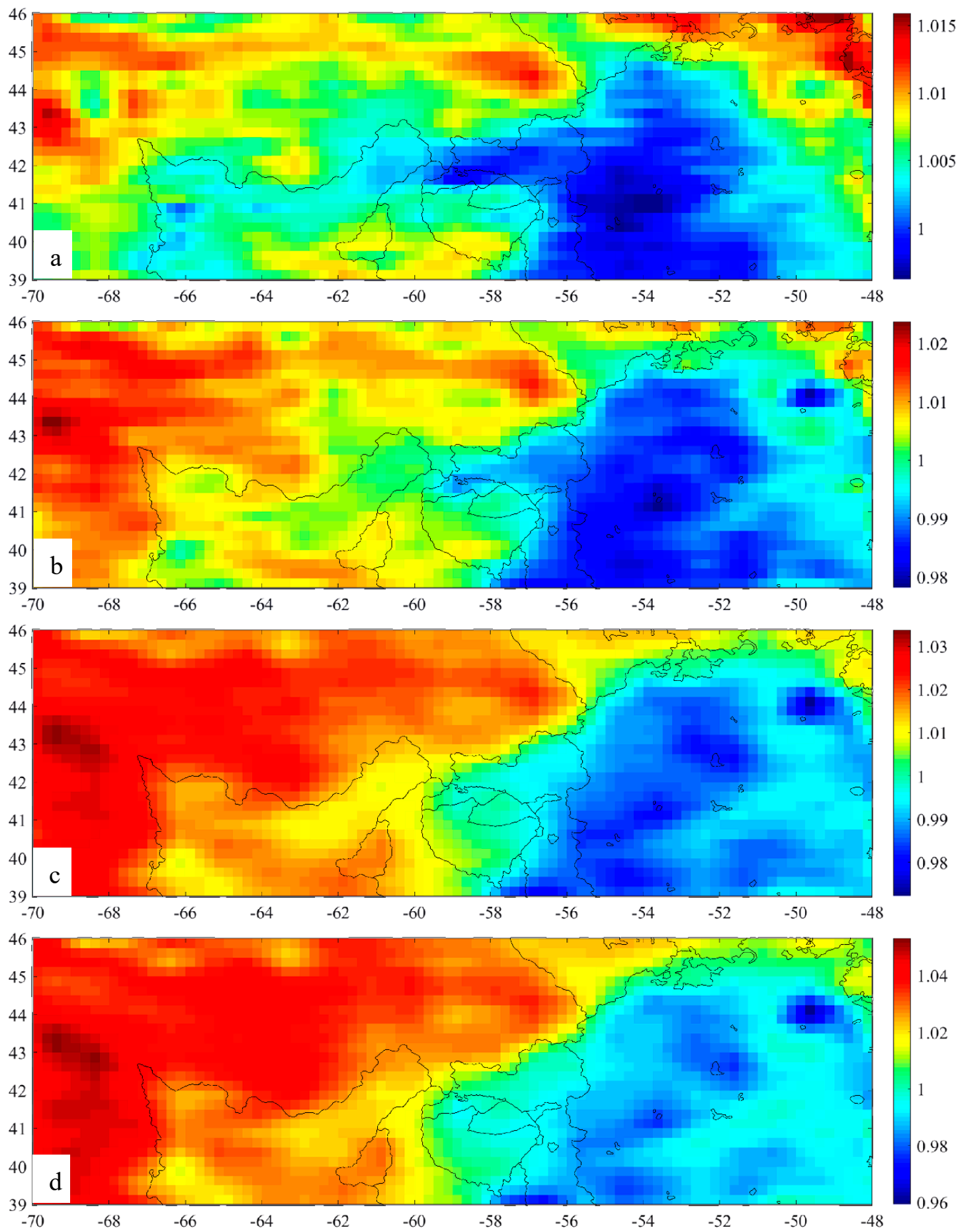

Figure 5. Normalized TB maps at night: (a) $3.0 \mathrm{GHz}$, (b) $7.8 \mathrm{GHz}$, (c) $19.35 \mathrm{GHz}$, and (d) $37.0 \mathrm{GHz}$. The black lines denote the geologic boundaries of Qian et al. [2].

\subsubsection{TB Difference (dTB) Maps}

The dTB maps are generated in this study (Figure 6). dTB is the difference between the noon TB and the night TB at the same frequency. It is directly related to the regolith thermophysical parameters within the penetration depth, because the majority change of the regolith temperature only happens at the uppermost $15 \mathrm{~cm}$ layer [30,32,33,40,41,51,52]. The dTB performances can be classified into four grades (Figure 6). Em4 has the highest dTB values, followed by Em3, and Im2 and Em2 have the 
lowest values. Moreover, the four-channel dTB maps describe well the change of the thermophysical features with depth in the lunar regolith, which is discussed in Section 4.
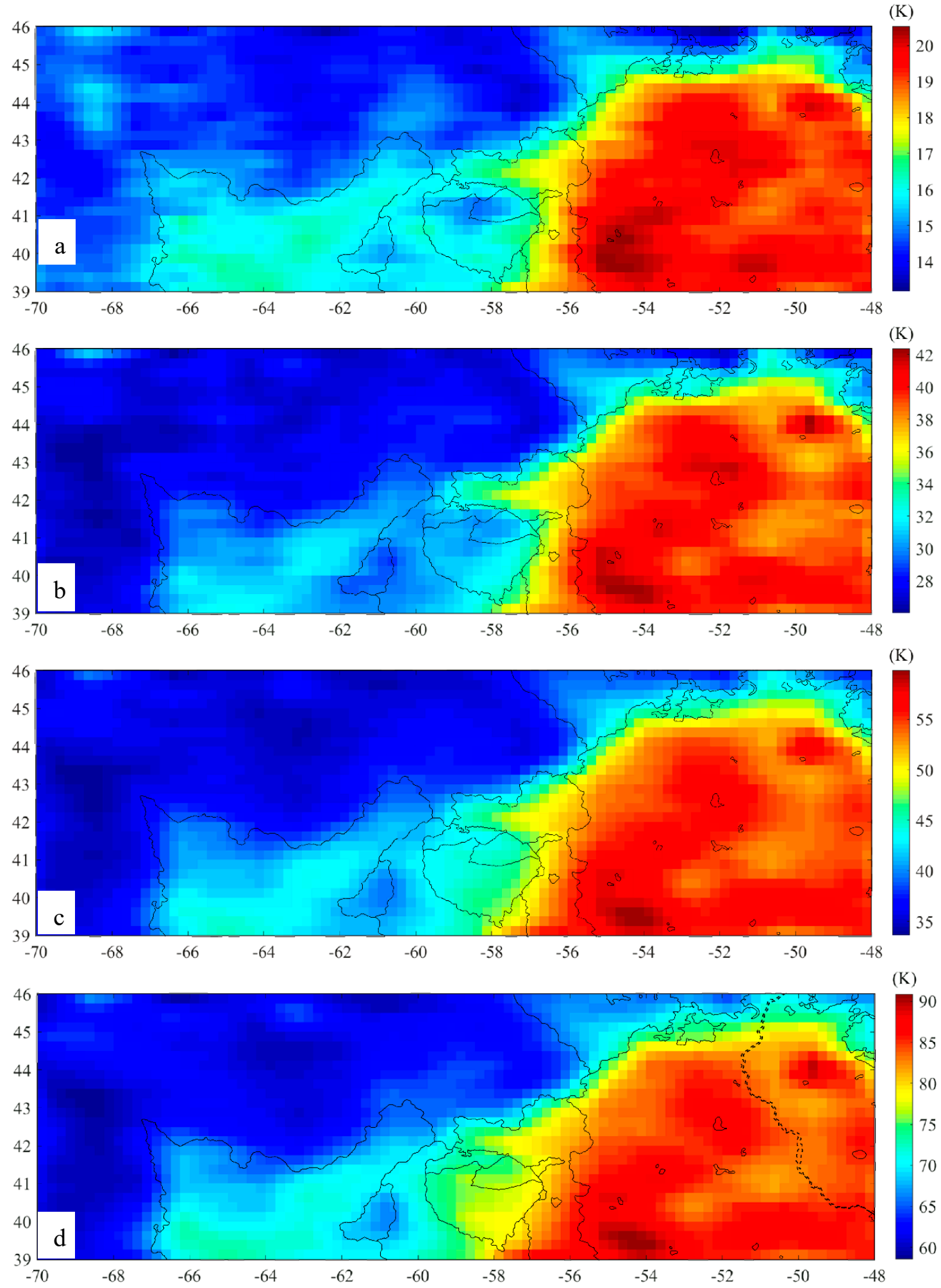

Figure 6. dTB Map of the Rümker region. (a) $3.0 \mathrm{GHz}$, (b) $7.8 \mathrm{GHz}$, (c) $19.35 \mathrm{GHz}$, and (d) $37.0 \mathrm{GHz}$. The black lines denote the geologic boundaries of Qian et al. [2]. The dashed line at Figure 6d indicates Rima Sharp, the longest sinuous rille on the Moon [18]. 


\subsubsection{Emissivity Maps}

The emissivity is the ratio between the observed TB and the surface temperature at the same time, which is directly related to the dielectric constant or density of the lunar regolith [43]. The soil temperature (ST) product at night is used in this study to calculate the data for the emissivity maps [45], with a temperature resolution of $0.02 \mathrm{~K}$ and a spatial resolution of 128 pixels/degree. This dataset is available from PDS Geosciences Node (https://ode.rsl.wustl.edu/moon/index.aspx). The ST product is the average temperature in Kelvin, nighttime hourly and all hours averaged together. However, the raw data value is from $-40 \mathrm{~K}$ to $40 \mathrm{~K}$. This is the direct surface temperature parameter of the lunar regolith. The ST is added $273 \mathrm{~K}$ in this study to better describe the thermal emission features of the mare units in the Rümker region (Figure 7a). Then, the ratio between the $37 \mathrm{GHz}$ nighttime TB and the ST product can be assigned as the nighttime emissivity of the mare deposits (Figure $7 \mathrm{~b}$ ).
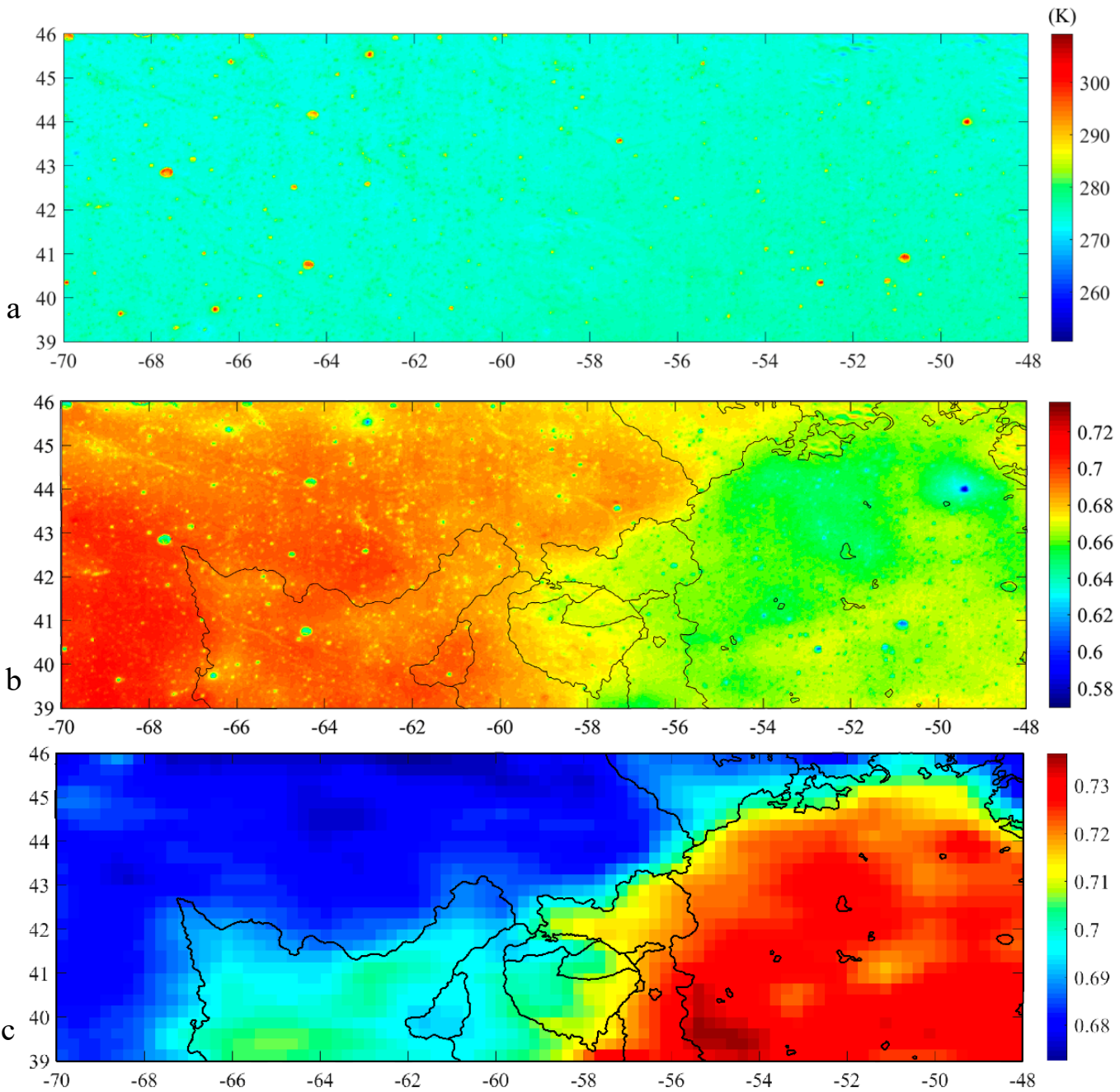

Figure 7. (a) LRO Diviner surface temperature product, (b) nighttime emissivity, and (c) noon emissivity maps of the Rümker region. The black lines denote the geologic boundaries of Qian et al. [2].

Meng et al. $[51,53]$ proposed that the generated TB divided by the simulated surface temperature can be used to represent the emissivity of the lunar regolith at the corresponding frequency, which is essential to evaluate the regolith thermophysical features of the related penetration depth. Here, the surface temperature is estimated with the method provided by Meng et al. [46], and the CE-1 (Laser Altimeter) LAM data is used as the surface elevation on the condition of 1:30 p.m., in the middle of the observation time for the CELMS used data at 1 a.m. to 2 a.m.. Then, the ratio between the 
generated $37 \mathrm{GHz} \mathrm{TB}$ and the simulated surface temperature is assigned as the noon emissivity of the mare deposits (Figure 7c).

Compared to the primary TB values (Figure 3), the emissivity maps provide new views of the Rümker region. The clear geologic boundaries between $\operatorname{Im} 2$, Im3, and $\mathrm{Em} 3$ indicate that the generated emissivity maps are realistic. However, it should be noted that:

(1) The Diviner surface temperature is the original data plus $273 \mathrm{~K}$ (not the real night emissivity), but it is valuable to study the relative distribution of the regolith thermophysical features comparatively.

(2) There are abundant crater-related spots with abnormally high emissivity at night, but the study of their abnormal emissivity is not feasible, because of the rather low resolution of CELMS (1 degree/pixel) compared to the Diviner data (128 pixels/degree).

Even so, the LRO Diviner data is better than the simulated surface temperature, because it is the direct measurement of the temperature of the mare basalts. In this study, only the emissivity map at $37 \mathrm{GHz}$ is employed, and the application of the emissivity should be critical.

\subsubsection{Reliability Analysis}

For the CELMS was the first orbital instrument to measure the microwave thermal emission of the lunar regolith [54], no similar data is available to evaluate the reliability of the generated nTB, dTB, and emissivity maps. Thus, the following three ways are used to comparatively evaluate the rationality of the generated nTB, dTB, and emissivity maps.

Firstly, the generated TB maps agree well with the previous global TB maps provided by Chan et al. [50], Zheng et al. [35,49], Cai and Lan [48], and Zhu et al. [55] in values and geographic distribution.

Secondly, the TB and nTB in Em4 are higher than Im2 at noon, while they are lower than $\operatorname{Im} 2$ at night. Moreover, the dTB in Em4 is higher than Im2. Because the FTA in Em4 is higher than Im2 [2], the $\mathrm{TB}, \mathrm{nTB}$, and $\mathrm{dTB}$ performances coincide well with the simulation results in Section 2.

Thirdly, Figures 4-6 show that, in general, the correspondence between the mare units and the $\mathrm{nTB}$ and dTB performances is not perfect. Even so, the boundary between $\operatorname{Im} 2$ and other adjacent units is well seen in the nTB and ATB maps. In addition, the nTB and dTB performances are largely good expressed in Im1, Im3, Em2, and Em4 units and Mons Rümker. What is more, the geologic boundaries are also shown by the emissivity maps.

In summary, the generated $\mathrm{nTB}, \mathrm{dTB}$, and emissivity maps should be reliable. The special nTB performances at noon and night and the $\mathrm{dTB}$ maps present several good descriptions of the thermophysical features of mare units. The nTB and dTB performances at the four channels indicate a good description of the regolith thermophysical parameters in vertical direction.

To further understand the thermophysical features of the mare units in the Rümker region, the TB maps at 1 a.m., 7 a.m., 12 p.m., 4 p.m., 6 p.m., 8 p.m., and 10 p.m. are also generated in this study, which are used as frames of reference in the following discussions.

\section{3. $\mathrm{FeO}$ and $\mathrm{TiO}_{2}$ Abundances}

As mentioned before, the $\mathrm{FeO}$ and $\mathrm{TiO}_{2}$ abundances are the decisive factors for the $\mathrm{TB}$ of the mare units [42,56]. To address this issue, the $\mathrm{FeO}$ and $\mathrm{TiO}_{2}$ abundance maps (Figure 8) are derived from the Kaguya Multiband Imager (MI) data (five VIS bands at 415, 750, 900, 950, and 1000 nm; 20 m/pixel) following the methods of Otake et al. [47]. Kaguya MI data is available from the SELENE Data Archive (http://darts.isas.jaxa.jp/planet/pdap/selene/).

The $\mathrm{FeO}$ and $\mathrm{TiO}_{2}$ abundance maps (Figure 8) show that $\mathrm{Em} 4$ has the highest $\mathrm{FeO}$ and $\mathrm{TiO}_{2}$ abundances, followed by $\operatorname{Im} 1$, Em1, and Em3 units, and $\operatorname{Im} 2$ has the lowest values. Linear anomalies distributed along northwest and northeast directions indicate the presence of secondary craters and rays formed by foreign materials excavated by distant craters and laterally delivered to the region $[2,26]$. 

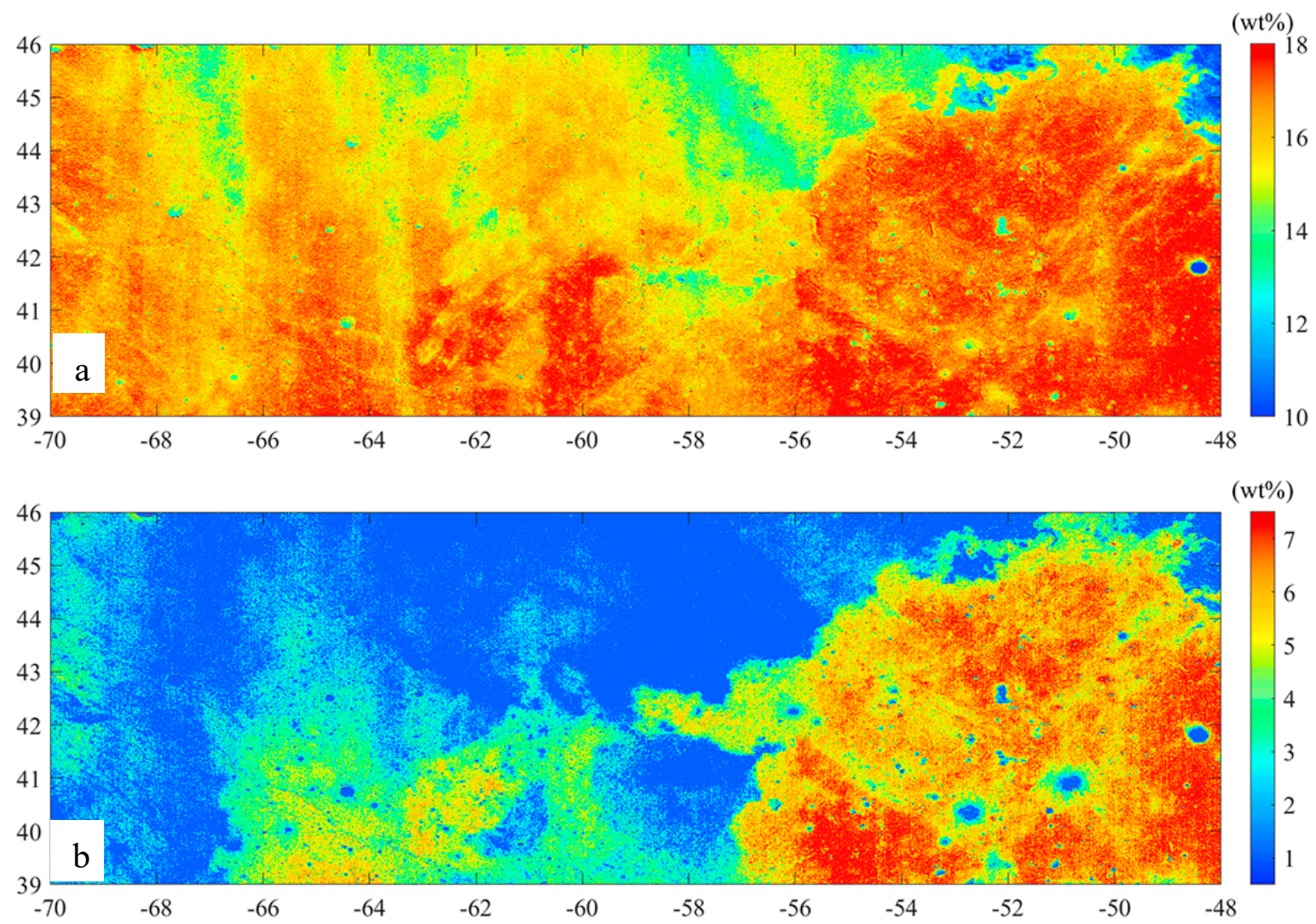

Figure 8. $\mathrm{FeO}(\mathbf{a})$ and $\mathrm{TiO}_{2}(\mathbf{b})$ abundances of the Rümker region.

\section{Results}

\subsection{Imbrian-Aged Mare Units}

$\operatorname{Im} 1, \operatorname{Im} 2$, and $\operatorname{Im} 3$ are Imbrian-aged mare units [2,14,57], which have relatively lower nTB values at noon, higher nTB values at night, and lower dTB values than their younger Eratosthenian-aged counterparts.

$\operatorname{Im} 1$ is the oldest mare unit $(\sim 3.42 \mathrm{Ga})$ in the southwestern part of the Rümker region [2]. Im1 has the third highest nTB at noon, and the nTB in its southern part is higher than that in the northern part (Figure 4). At night, $\operatorname{Im} 1$ has the third highest nTB in the extensive region at $3.0 \mathrm{GHz}$ (Figure 5), while it is the second highest at the other three channels. The nighttime nTB in the central part is higher than its surroundings, distributed along a northwest direction, but lower than that in the $\operatorname{Im} 2$ unit. This appears at $7.8 \mathrm{GHz}, 19.35$, and $37 \mathrm{GHz}$ but not at $3.0 \mathrm{GHz}$, suggesting the deposits at the surface are likely different from those at depth (larger $76.9 \mathrm{~cm}$ revealed by the $7.8-\mathrm{GHz}$ microwave but less than $1 \mathrm{~m}$ indicated by the $3.0-\mathrm{GHz}$ microwave). Figure 6 indicates that $\operatorname{Im} 1$ has the third highest dTB in this unit. The dTB in the northern part is several Kelvins lower than that in the southern part at $7.8,19.35$, and $37 \mathrm{GHz}$, and the $\mathrm{dTB}$ in the whole $\operatorname{Im} 1$ is homogeneously higher than $\operatorname{Im} 2$ at $3.0 \mathrm{GHz}$. These findings mean that the mare deposits in the northern part are heavily influenced by the ejecta from the Im2 unit in the shallow layer. This conclusion is supported by the emissivity (Figure 7) and compositional maps (Figure 8), where the boundary between $\operatorname{Im} 1$ and $\operatorname{Im} 2$ is not clear.

$\operatorname{Im} 2(\sim 3.39 \mathrm{Ga})$ is the largest mare unit in the western and northwestern parts of the Rümker region. Im2 has the lowest nTB at noon (Figure 4), the highest nTB at night (Figure 5), and the lowest dTB values (Figure 6), respectively. The nTB and dTB performances agree well with their lowest FeO and $\mathrm{TiO}_{2}$ abundances according to the numerical simulation (Section 2). The nTB at 3.0 and $7.8 \mathrm{GHz}$ in the northwestern part is relatively higher than that of the rest, no matter whether at noon or night. Notably, the noon nTB map (Figure 4) indicates a special region with considerably lower nTB centered 
at $\left(63^{\circ} \mathrm{W}, 43.5^{\circ} \mathrm{N}, \sim 70 \mathrm{~km}\right.$ in diameter). The nighttime $\mathrm{nTB}$ of this region is relatively lower than other places in this unit at 3.0 and $7.8 \mathrm{GHz}$ but similar as the nearby place at other channels, indicating that this is a hidden structure. Furthermore, at 19.35 and $37 \mathrm{GHz}$, the nTB in the southwestern part is lowest at noon but highest at night. $\operatorname{Im} 2$ has the lowest dTB values compared to the other units (Figure 6). Here, the special nTB performances in the northwestern, southwestern, and that centered at $\left(63^{\circ} \mathrm{W}\right.$, $43.5^{\circ} \mathrm{N}$ ) are confirmed by the dTB maps, indicating the inhomogeneity of the mare deposits in $\operatorname{Im} 2$. $\operatorname{Im} 2$ has a higher nighttime emissivity but lower noon emissivity values (Figure 7).

$\operatorname{Im} 3(\sim 3.16 \mathrm{Ga})$ is located in the northeastern parts of the Rümker region. The noon nTB in Im3 is higher than Im2 but lower than Em4, while the nighttime nTB is lower than Im2 but higher than Em4. The dTB is similar to that in $\operatorname{Im} 1$ at noon. In addition, the dTB in the southern part of $\operatorname{Im} 3$ is higher than that in the northern part. The night emissivity of $\operatorname{Im} 3$ is lower than $\operatorname{Im} 2$ but higher than Em4 (Figure 7), and the geologic boundaries are well consolidated in this unit.

Mean values of TB, nTB, and dTB of the Imbrian-aged mare basalts are summarized in Table 1. Table 1 shows that the nTB is lowest in $\operatorname{Im} 2$ at noon and highest at night, while the nTB is highest in $\operatorname{Im} 1$ at noon and it is lowest in $\operatorname{Im} 3$ at night. The mean dTB is highest in $\operatorname{Im} 1$, followed by $\operatorname{Im} 3$ and Im2. The dTB and nTB performances in $\mathrm{Im} 2$ agree well with its low $\mathrm{FeO}$ and $\mathrm{TiO}_{2}$ abundances (Figure 8) according to the numerical simulation (Section 2). However, the nTB performances in Im1 and $\operatorname{Im} 3$ are difficult to explain and are not consistent with the numerical simulation. We will discuss this phenomenon in Section 5.

Table 1. The mean $\mathrm{TB}$, $\mathrm{nTB}$, and $\mathrm{dTB}$ values of the $\operatorname{Im} 1, \operatorname{Im} 2$, and $\operatorname{Im} 3$ units.

\begin{tabular}{|c|c|c|c|c|c|c|}
\hline \multirow{2}{*}{$\begin{array}{c}\text { Channel } \\
\text { (GHz) }\end{array}$} & \multirow{2}{*}{ Units } & \multicolumn{2}{|c|}{ TB (K) } & \multirow{2}{*}{ dTB (K) } & \multicolumn{2}{|c|}{ nTB } \\
\hline & & Night & Noon & & Night & Noon \\
\hline \multirow{3}{*}{3.0} & $\operatorname{Im} 1$ & 203.8 & 219.8 & 16.0 & 1.0070 & 1.0262 \\
\hline & $\operatorname{Im} 2$ & 199.6 & 213.8 & 14.2 & 1.0082 & 1.0178 \\
\hline & $\operatorname{Im} 3$ & 197.5 & 212.9 & 15.4 & 1.0052 & 1.0223 \\
\hline \multirow{3}{*}{7.8} & $\operatorname{Im} 1$ & 189.3 & 220.0 & 30.7 & 1.0070 & 1.0412 \\
\hline & $\operatorname{Im} 2$ & 185.0 & 212.2 & 27.3 & 1.0096 & 1.0272 \\
\hline & $\operatorname{Im} 3$ & 181.4 & 212.0 & 30.5 & 1.0023 & 1.0365 \\
\hline \multirow{3}{*}{19.35} & $\operatorname{Im} 1$ & 205.4 & 247.6 & 42.2 & 1.0161 & 1.0286 \\
\hline & $\operatorname{Im} 2$ & 203.2 & 238.4 & 35.1 & 1.0230 & 1.0102 \\
\hline & $\operatorname{Im} 3$ & 199.0 & 239.3 & 40.4 & 1.0097 & 1.0235 \\
\hline \multirow{3}{*}{37.0} & $\operatorname{Im} 1$ & 190.6 & 260.3 & 69.7 & 1.0283 & 1.0162 \\
\hline & $\operatorname{Im} 2$ & 189.4 & 250.2 & 60.8 & 1.0393 & 0.9972 \\
\hline & $\operatorname{Im} 3$ & 184.4 & 252.1 & 67.7 & 1.0195 & 1.0140 \\
\hline
\end{tabular}

Qian et al. [2] suggested that NE-orientated Pythagoras secondary ejecta may appear in Imbrian-aged mare units based on surface compositions (Figure 8); however, these linear features are not presented in the TB, nTB, and dTB maps, indicating the CELMS data is weakly affected by the ejecta or the ejecta layer is relatively thin.

\subsection{Eratosthenian-Aged Mare Units}

Em1, Em2, Em3, and Em4 are Eratosthenian-aged mare units [2], which have relatively higher $\mathrm{nTB}$ at noon, lower nTB at night, and higher dTB values, corresponding to their higher $\mathrm{FeO}$ and $\mathrm{TiO}_{2}$ abundances.

Em1 ( 2.30 Ga) embays Mons Rümker in the southwest, which presents the third highest nTB at noon and the second highest $\mathrm{nTB}$ at night as same as Im1. At noon, there is a small region with fairly 
low nTB at $3.0 \mathrm{GHz}$ in the western part adjacent to the Em2 unit, and the area of this special region increases with the frequency. At night, the nTB becomes homogeneous at 19.35 and $37 \mathrm{GHz}$. The dTB maps indicate that the values here are lower than that in Em4 but higher than that in Im2. Moreover, the unit presents a largely homogeneous dTB distribution, and the values are very similar to those in $\operatorname{Im} 1$. The difference between Em1 and Im1 units is also not clear in the emissivity maps (Figure 7).

$\operatorname{Em} 2(\sim 2.13 \mathrm{Ga})$ is a small patch in the middle southern part, which is surrounded by $\operatorname{Im} 1$ to the west and Em1 to the east. Em2 has the nearly lowest nTB at noon and highest at night as that in Im2 except for $3.0 \mathrm{GHz}$ map (Figures 4 and 5). At $3.0 \mathrm{GHz}$, the nTB is similar to the nearby units. In dTB maps, most part of Em2 unit is similar to $\operatorname{Im} 1$ and $\mathrm{Em} 1$ units at $3.0 \mathrm{GHz}$, but it is lower than $\operatorname{Im} 1$ and Em1 units at the other three channels. This means that the thermophysical features of the mare deposits in Em2 change significantly with depth.

Em3 $(\sim 1.51 \mathrm{Ga})$ is located to the east of Mons Rümker, whose thermophysical features are complex. At noon, the place adjacent to $\operatorname{Em} 4$ has the highest nTB, the place adjacent to $\operatorname{Im} 2$ has the third highest $\mathrm{nTB}$, and the remaining place displays the second highest nTB (Figure 4). At night, the extensive area has the lowest nTB at 3.0 and $7.8 \mathrm{GHz}$ as Em4, while it has the third lowest nTB at 19.35 and $37 \mathrm{GHz}$. The dTB is highest in the place adjacent to Em4, it is the third highest in the place adjacent to Im2, and it is the second highest in the remaining areas. Thus, Em3 is in the transition from the Ti-rich Em4 unit to the Ti-poor $\operatorname{Im} 2$ unit, and the change of the regolith thermophysical features with depth is great in the horizontal direction.

Em4 $(\sim 1.21 \mathrm{Ga})$ is the youngest mare unit in the eastern part of the Rümker region, and indicates the highest nTB at noon, lowest nTB at night, and highest $\mathrm{dTB}$ values. These nTB and dTB performances agree well with the highest $\mathrm{FeO}$ and $\mathrm{TiO}_{2}$ abundances according to the numerical simulation (Section 2). $\mathrm{TB}, \mathrm{nTB}$, and $\mathrm{dTB}$ maps show that the mare deposits are not homogeneous in this unit (Figures 4-6). The following several observations have been made.

(1) At noon, the $3.0 \mathrm{GHz}$ nTB in the central and northwestern parts is lower than the remaining area, while they become homogeneously high in the other three channels. At night, the nTB in the western part is lower than that in the eastern part. In addition, the dTB of Em4 in the western and southern parts is homogeneously high (Figure 6).

(2) There exist relatively higher noontime nTB and dTB areas centered at $\left(54.5^{\circ} \mathrm{W}, 39.5^{\circ} \mathrm{N}\right)$ and $\left(49.5^{\circ} \mathrm{W}, 44.5^{\circ} \mathrm{N}\right)$, and their nTB at night is considerably low. The numerical simulation (Section 2) suggests that the FTA here should be very high in such conditions [40,42]. As shown by Figure 8, the $\mathrm{FeO}$ and $\mathrm{TiO}_{2}$ abundances are highest in the region centered at $\left(54.5^{\circ} \mathrm{W}, 39.5^{\circ} \mathrm{N}\right)$, agreeing with the numerical simulation. However, the special TB values in the region centered at $\left(49.5^{\circ} \mathrm{W}\right.$, $44.5^{\circ} \mathrm{N}$ ) are not supported by the $\mathrm{FeO}$ and $\mathrm{TiO}_{2}$ maps.

(3) There occur relatively lower noontime $\mathrm{nTB}$ and $\mathrm{dTB}$ values in two patches centered at $\left(53.0^{\circ} \mathrm{W}\right.$, $\left.40.5^{\circ} \mathrm{N}\right)$ and $\left(51.0^{\circ} \mathrm{W}, 41.0^{\circ} \mathrm{N}\right)$. In the optical images, they are two craters with diameters of $3.9 \mathrm{~km}$ and $5.8 \mathrm{~km}$, respectively, excavating underlying low $\mathrm{FeO}$ and $\mathrm{TiO}_{2}$ materials. However, the area of the regions with relatively lower $\mathrm{dTB}$ is much more extensive than the craters range. Particularly, at 7.8, 19.35, and $37 \mathrm{GHz}$ maps, the regions with relatively lower $\mathrm{dTB}$ extend to the east and north directions. Interestingly, Rima Sharp, the longest sinuous rille on the Moon [18] extends across the western part of the low-dTB zone (Figure 6d).

The mean TB, nTB, and dTB values of the Eratosthenian-aged mare basalts are summarized in Table 2. Table 2 indicates that the mean noontime nTB is highest in Em4, followed by Em3, Em1, and Em2. The mean dTB supports this sequence. The mean nighttime nTB indicates an inverse sequence, and it is highest in Em2, followed by Em1, Em3, and Em4. These TB performances agree perfectly with the numerical simulation by Meng et al. [30,42,51], who proposed that the regions with higher $\mathrm{FeO}$ and $\mathrm{TiO}_{2}$ abundances will display a higher $\mathrm{TB}$ in the daytime, a lower $\mathrm{TB}$ at night, and higher dTB values, supported by Qian et al. [2]'s $\mathrm{TiO}_{2}$ and $\mathrm{FeO}$ measurement (Figure 8). The sequence of the four units is critical to understand the basaltic volcanism in the Rümker region. 
Table 2. The mean TB, nTB, and dTB values of the Em1, Em2, Em3, and Em4 units.

\begin{tabular}{|c|c|c|c|c|c|c|}
\hline \multirow{2}{*}{$\begin{array}{c}\text { Channel } \\
\text { (GHz) }\end{array}$} & \multirow{2}{*}{ Units } & \multicolumn{2}{|c|}{ TB (K) } & \multirow{2}{*}{ dTB (K) } & \multicolumn{2}{|c|}{ nTB } \\
\hline & & Night & Noon & & Night & Noon \\
\hline \multirow{4}{*}{3.0} & Em1 & 204.28 & 219.99 & 15.71 & 1.0070 & 1.0256 \\
\hline & Em2 & 204.18 & 219.56 & 15.38 & 1.0077 & 1.0248 \\
\hline & Em3 & 200.22 & 217.74 & 17.52 & 1.0001 & 1.0272 \\
\hline & Em4 & 199.83 & 219.41 & 19.58 & 0.9998 & 1.0366 \\
\hline \multirow{4}{*}{7.8} & Em1 & 189.16 & 219.31 & 30.15 & 1.0045 & 1.0362 \\
\hline & Em2 & 189.29 & 218.51 & 29.22 & 1.0066 & 1.0338 \\
\hline & Em3 & 183.67 & 219.68 & 36.01 & 0.9905 & 1.0523 \\
\hline & Em4 & 182.50 & 222.59 & 40.09 & 0.9861 & 1.0680 \\
\hline \multirow{4}{*}{19.35} & Em1 & 204.59 & 246.54 & 41.95 & 1.0111 & 1.0230 \\
\hline & Em2 & 205.71 & 245.38 & 39.67 & 1.0176 & 1.0193 \\
\hline & Em3 & 199.16 & 248.48 & 49.317 & 0.9946 & 1.0435 \\
\hline & Em4 & 196.95 & 252.62 & 55.67 & 0.9848 & 1.0625 \\
\hline \multirow{4}{*}{37.0} & Em1 & 188.59 & 259.26 & 70.67 & 1.0167 & 1.0108 \\
\hline & Em2 & 190.82 & 257.44 & 66.62 & 1.0297 & 1.0049 \\
\hline & Em3 & 183.30 & 262.25 & 78.95 & 0.9980 & 1.0354 \\
\hline & Em4 & 180.73 & 266.05 & 85.32 & 0.9853 & 1.0520 \\
\hline
\end{tabular}

\subsection{Rümker Plateau Units}

IR1, IR2, and IR3 are Rümker plateau units [1], which have the third highest nTB at noon and night and a complex dTB performance.

IR1 $(\sim 3.71 \mathrm{Ga})$ is a lineated terrain in the northern and northeast part of Mons Rümker, formed by mixing of Iridum crater ejecta and basaltic materials. IR1 has much lower noon TB in the northern part than IR2 and IR3 (Figure 4). The nTB in the northern part has lowest values at 3.0 and $7.8 \mathrm{GHz}$, while it is similarly as low as IR2 and IR3 at 19.35 and $37 \mathrm{GHz}$ (Figure 5). The dTB maps (Figure 6) in the northern part show that IR1 has similar values to IR2 and IR3 at 3.0, 7.8, and $19.35 \mathrm{GHz}$, while it is a bit lower than IR2 and IR3 at $37 \mathrm{GHz}$. Moreover, the difference of the TB performances between the IR1 in the northeastern part and the nearby Em3 is hard to identify in the NTB and dTB maps.

IR2 ( 3.58 Ga) is in the northeast part of Mons Rümker between two IR1 patches, exhibiting lower $\mathrm{TiO}_{2}$ contents. As shown by Figure 4, the noon nTB at $3.0 \mathrm{GHz}$ and $7.8 \mathrm{GHz}$ is similarly as low as IR1, while it is similarly high as IR3 at $19.35 \mathrm{GHz}$ and $37 \mathrm{GHz}$. Figure 5 shows that the nighttime nTB in IR2 is higher than IR1 at $3.0 \mathrm{GHz}, 7.8 \mathrm{GHz}$, and $19.35 \mathrm{GHz}$ but lower than the IR3 unit. At $37 \mathrm{GHz}$, the nTB in IR2 becomes similar to IR1 and IR3. The western part of IR2 has the lowest dTB over Mons Rümker only at $3.0 \mathrm{GHz}$, while the dTB in the remaining part of IR2 is as high as IR1 and IR3 (Figure 6).

IR3 ( 3.51 Ga) occupies the main portion of Mons Rümker, and $\mathrm{FeO}$ and $\mathrm{TiO}_{2}$ abundances are higher than IR1 and IR2. The northern part of IR3 has low noon nTB as IR2 and IR3 at $3.0 \mathrm{GHz}$ and the nTB in the southern part of IR3 is the highest in Mons Rümker (Figure 4). Figure 5 shows that the night nTB in IR3 is similar to IR1 and IR2 besides $3.0 \mathrm{GHz}$, while the nTB in the southern part of IR3 is still higher than the rest part of Mons Rümker. The dTB in the northern part of IR3 is similarly low as the western part of IR2 at $3.0 \mathrm{GHz}$, while the dTB difference among IR1, IR2, and IR3 is not clear at 7.8 GHz, 19.35 GHz, and $37 \mathrm{GHz}$ (Figure 6).

The mean values of TB, nTB, and dTB of the Rümker plateau units are summarized in Table 3 . Table 3 indicates that the mean noontime nTB is highest in IR3, followed by IR2 and IR1. This agrees with the numerical simulation as mentioned before, since the $\mathrm{FeO}$ and $\mathrm{TiO}_{2}$ contents are highest in 
the IR3 unit, followed by the IR2 and IR1 [1]. However, the nTB at night is difficult to understand, for the nTB in IR3 is still highest, followed by IR2 and IR1, which is opposite to the aforementioned numerical simulation. Additionally, the ATB in IR3 is highest, followed by IR2 and IR1 at 19.35 and $37 \mathrm{GHz}$; but the dTB in IR2 is lower than IR1 at 3.0 and $7.8 \mathrm{GHz}$.

Table 3. The mean TB, nTB, and dTB values of the IR1, IR2, and IR3 units.

\begin{tabular}{|c|c|c|c|c|c|c|}
\hline \multirow{2}{*}{$\begin{array}{c}\text { Channel } \\
\text { (GHz) }\end{array}$} & \multirow{2}{*}{ Units } & \multicolumn{2}{|c|}{ TB (K) } & \multirow{2}{*}{ dTB (K) } & \multicolumn{2}{|c|}{ nTB } \\
\hline & & Night & Noon & & Night & Noon \\
\hline \multirow{3}{*}{3.0} & IR1 & 200.70 & 216.70 & 16.00 & 0.9987 & 1.0188 \\
\hline & IR2 & 202.11 & 217.36 & 15.25 & 1.0042 & 1.0206 \\
\hline & IR3 & 203.44 & 219.49 & 16.05 & 1.0056 & 1.0244 \\
\hline \multirow{3}{*}{7.8} & IR1 & 184.70 & 215.60 & 30.90 & 0.9916 & 1.0287 \\
\hline & IR2 & 186.33 & 216.65 & 30.32 & 0.9986 & 1.0321 \\
\hline & IR3 & 188.00 & 218.97 & 30.97 & 1.0020 & 1.0376 \\
\hline \multirow{3}{*}{19.35} & IR1 & 200.60 & 243.74 & 43.14 & 0.9988 & 1.0202 \\
\hline & IR2 & 201.19 & 245.50 & 44.31 & 1.0006 & 1.0262 \\
\hline & IR3 & 202.53 & 247.43 & 44.90 & 1.0031 & 1.0293 \\
\hline \multirow{3}{*}{37.0} & IR1 & 183.87 & 257.04 & 73.17 & 0.9982 & 1.0112 \\
\hline & IR2 & 184.25 & 259.34 & 75.09 & 0.9992 & 1.0188 \\
\hline & IR3 & 185.21 & 261.76 & 76.55 & 1.0005 & 1.0232 \\
\hline
\end{tabular}

Moreover, three issues about Mons Rümker should be mentioned.

(1) The differences between IR1, IR2, and IR3 are rather slight compared to the mare basaltic units. We observed a relatively lower nTB in IR1 and a higher nTB in the southern part of IR3. Considering the large topographic fluctuation typical of Mons Rümker, the influence of the topography on TB should be taken into account. Here, the TB is enhanced in the southern part of IR3 for the surface slopes oriented to the solar illumination, and it is weakened in IR1 with the surface slopes opposite to the solar illumination. This implies that the elevated nTB in the south and the decreased nTB in the north are caused by the surface topography, for the effective solar illumination will be enhanced in the south and weakened in the north [29,46]. Additionally, the noon emissivity in Figure 7c also gives similar values in IR1, IR2, and IR3. This means that the low nTB in IR1 and the high nTB in the southern part of IR3 at noon are caused by the surface topography. The dTB maps effectively weaken the influence of the surface topography, which is better to describe the thermophysical features of the mare units. Thus, the similar dTB and noon emissivity values in IR1, IR2, and IR3 are likely to mean that the thermophysical features of the mare deposits in Mons Rümker are homogeneous.

(2) A small patch centered at $\left(58.5^{\circ} \mathrm{W}, 41.3^{\circ} \mathrm{N}\right)$ with rather low dTB at $3.0 \mathrm{GHz}$, including the aforementioned western part of IR2 and the northern part of IR3, should be noticed. The influence of the topography on the low-dTB anomaly can be excluded for the reason mentioned above. IR1 is in the slope opposite to the solar illumination and the ATB in IR1 is still higher than that in the patch. Thus, this low-dTB anomaly should be resulted from the thermophysical features of a special mare deposit. However, the anomaly is absent at the other three channels, indicating that this is a hidden construct on Mons Rümker.

(3) We proposed that the nTB performances in Mons Rümker are abnormal. According to the numerical simulation, the mafic-rich deposit will have a higher TB at noon but a lower TB at night. However, the TB in IR3 is higher than IR1 no matter at noon or night. This means that the 
thermophysical features of the mare deposits in Mons Rümker are different from the Imbrian-aged and Eratosthenian-aged mare units, which should be interpreted to be an independent unit.

\subsection{Other Units}

Qian et al. [2] suggested that there also exists a highland unit and an Imbrian-aged dome unit in the study area, which is outlined and overlaid on the nTB and ATB maps. However, no special TB variations occur in these units.

This is mainly due to the low spatial resolution of the original CELMS data, which is about a degree per pixel. At such a scale, outcrops of the highland unit and the Imbrian-aged dome unit with small areas are not detected by the CELMS instrument. In addition, China's CE-5 mission will not land on these units as the sampling sites.

Therefore, the thermophysical features of the two units are not discussed in this study.

\section{Discussions}

The generated nTB and dTB maps from CE-2 CELMS data give us a new view about the basaltic volcanism and sampling sites in Rümker region.

\subsection{New Views of Geologic Units}

The Rümker region, located in the anomalous Procellarum KREEP Terrane [5], is the site of volcanic activity of an extended duration (from Late Imbrian Period to Eratosthenian Period), forming an extensive mare basalt plain in the area $[1,2,14,16]$. Different authors have mapped the geological units in the Rümker region using different datasets, e.g., Clementine UVVIS data $[14,16,23]$ and Kaguya MI data [1,2]. However, all of the previous studies rely on optical reflectance for subdividing geological units, which inevitably ignores the internal structure of a geological unit [26]. The CE-2 CELMS TB (Figure 3), nTB (Figures 4 and 5), and dTB data (Figure 6) provide a new opportunity to gain insight into the geological units in the region, and these data and implications for the units are discussed below.

Firstly, the Im2 unit divided by Qian et al. [2] is confirmed by the NTB and dTB performances and its performances agree with the numerical simulation (Section 2).

Secondly, the majority of the Em4 unit has high noon nTB, low nighttime nTB, and high dTB values, agreeing well with its highest $\mathrm{FeO}$ and $\mathrm{TiO}_{2}$ abundances according to the numerical simulation (Section 2). However, the unit may extend southwestwardly on the basis of the similar nTB and dTB performances (Figures 4-6); and its northern boundaries may extend more southwardly because the $\mathrm{nTB}$ at noon and dTB are lower than other places of the unit (Figures 5 and 6). However, considering the poor spatial resolution and the large penetration ability of the CELMS data, we maintain the geological boundary outlined by Qian et al. [2].

Thirdly, the difference between $\operatorname{Im} 1$ and Em 1 units is indistinguishable in the thermophysical data. The mean TB values and the change of the TB with time are nearly identical in the two units throughout the day (Figure 9). Additionally, the mean $\mathrm{TiO}_{2}(2.4 \mathrm{wt} \%)$ and $\mathrm{FeO}(16.8 \mathrm{wt} \%)$ abundances of $\mathrm{Em} 1$ are approximately the same as those of $\operatorname{Im} 1$ with $\mathrm{TiO}_{2}(2.4 \mathrm{wt} \%)$ and $\mathrm{FeO}(16.3 \mathrm{wt} \%)$ [2], and the emissivity in $\operatorname{Im} 1$ and Em 1 is similar. Therefore, $\operatorname{Im} 1$ and Em 1 can be combined into one thermophysical unit based on the above analysis. Because $\mathrm{Im} 1$ has clearly higher $\mathrm{FeO}$ and $\mathrm{TiO}_{2}$ abundances than Imbrian-aged $\operatorname{Im} 2$ and $\operatorname{Im} 3$, Im1 can be combined with Em1 in terms of their thermophysical properties.

Fourthly, the nTB of Em2 is distinctly different from the nearby $\operatorname{Im} 1$ and Em1 unit (lower at noon but higher at night). Notably, the nTB and dTB characteristics in Em2 are similar to Im2, which are apparently different from other units. The mean TB in Em2 indicates a similar behavior to $\operatorname{Im} 2$ as shown in Figure 10. It should be mentioned that the mean TB in Em2 is slightly higher than Im2 both in the daytime and at night, which probably could be explained by 1) the effective solar illumination in Em2 is higher than Im2 according to the numerical simulation [46,58,59], which makes the physical temperature in Em2 be higher than Im2; 2) the linear interpolation method to generate TB products (Figures 3-6) will smooth the difference of the nearby regions (the relatively higher TB surrounding 
Em2 at noon will enhance the difference of the TB between $\operatorname{Im} 2$ and Em2; the relatively lower TB surrounding Em2 at night will decrease the difference of the TB between $\operatorname{Im} 2$ and Em2). The change of the mean TB with time is nearly identical between Em2 and Im2 (Figure 10), suggesting similar thermophysical feature of the mare deposits. Thus, $\operatorname{Im} 2$ and $\mathrm{Em} 2$ can be described as one single thermophysical unit according to their $\mathrm{TB}, \mathrm{nTB}$, and $\mathrm{dTB}$ behaviors; this similarity is further supported by their similar $\mathrm{TiO}_{2}$ (1.6 wt. \%, Em2; 1.3 wt. \%, Im2) and $\mathrm{FeO}$ abundances (16.2 wt. \% Em2; 15.6 wt. \%). Considered the lower $\mathrm{FeO}$ and $\mathrm{TiO}_{2}$ abundances in Em2 compared with Em1, Em3, and Em4, Em2 is combined with Im2.

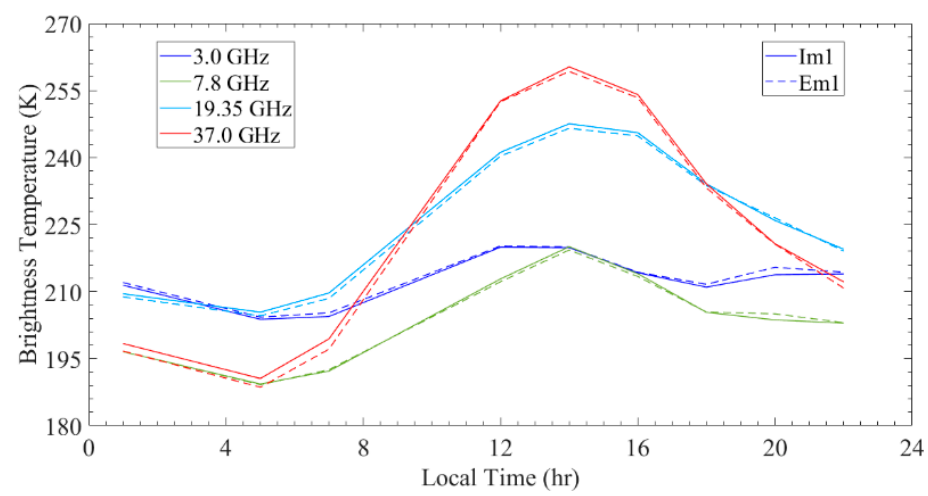

Figure 9. Change of TB with time in the $\operatorname{Im} 1$ and Em1 units. The data point is at 1 a.m., 5 a.m., 7 a.m., 12 p.m., 2 p.m., 4 p.m., 6 p.m., 8 p.m., and 10 p.m..

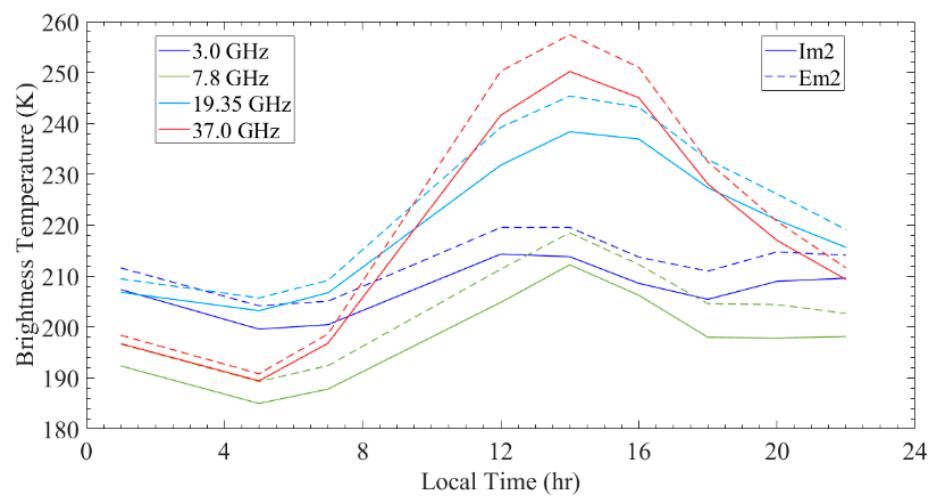

Figure 10. Change of mean TB with time in the $\operatorname{Im} 2$ and Em2 units. The data point is at 1 a.m., 5 a.m., 7 a.m., 12 p.m., 2 p.m., 4 p.m., 6 p.m., 8 p.m., and 10 p.m.

Fifthly, the nTB in Mons Rümker is the third highest at noon as Em1 on the west, while it is the third highest at night as Em3 on the east. Such TB performances are opposite to the numerical simulation, indicating that this is a special geologic zone. However, the difference between the three Rümker plateau units (IR1, IR2, and IR3) is indistinguishable. Figure 11 is the change of TB with time in IR1, IR2, and IR3. Although the TB of IR1 in the northern part is lower than that of IR3 in the southern part, the change tendencies of the three units are similar (Figure 11), indicating similar thermophysical parameters. Meng et al. $[30,44]$ suggested that the dTB values are slightly influenced by the surface topography, and the dTB is similar in the three units, particularly at 3.0, 19.35, and $37 \mathrm{GHz}$ maps. In addition, IR1, IR2, and IR3 have similar emissivities (Figure 7). Thus, the IR1, IR2, and IR3 should be ascribed to a single thermophysical unit, named IR on the basis of the above analysis. 


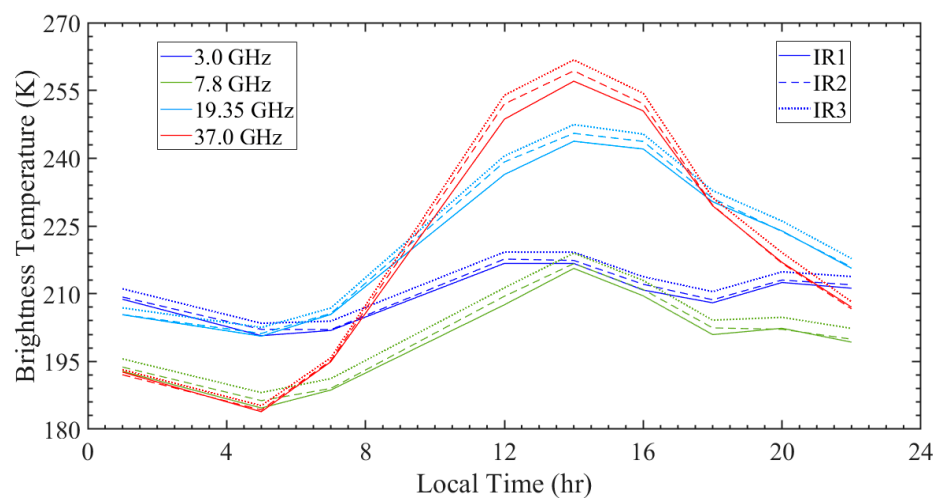

Figure 11. Change of mean TB with time in IR1, IR2, and IR3 units. The data point is at 1 a.m., 5 a.m., 7 a.m., 12 p.m., 2 p.m., 4 p.m., 6 p.m., 8 p.m., and 10 p.m.

One more notable point is that there occurs a small patch centered at $\left(58.5^{\circ} \mathrm{W}, 41.3^{\circ} \mathrm{N}\right)$ in Mons Rümker at 3.0 GHz dTB map as mentioned in Section 4.3, whose size is about $20 \mathrm{~km} \times 50 \mathrm{~km}$. The nTB and $\mathrm{dTB}$ at other channels are similar to its vicinity, indicating that this is a hidden terrain on Mons Rümker. We defined it as IRh unit.

Finally, the identification of Em3 is rather controversial, because Em3 has similar nTB and dTB behaviors to Em 4 on the east and similar behaviors to $\operatorname{Im} 1$ and $\mathrm{Em} 1$ on the west. A small range in the eastern part with similar TB characteristics to Em4 is revealed by the $3.0 \mathrm{GHz}$ nTB and dTB maps, with area becoming larger with the increasing frequency. This means that the regolith thermophysical parameters change greatly with depth in this unit. Interestingly, the emissivity in this unit is different from $\mathrm{Em} 4$ as seen in emissivity maps (Figure 7). In addition, Em3 has the relatively lower $\mathrm{FeO}$ and $\mathrm{TiO}_{2}$ abundances compared to Em4. Thus, we still maintain this unit in the new map. This unit is interpreted as a transition zone from the Ti-rich zone to Ti-poor zone.

Similar observations have also been made in Im3. The nTB at noon and the dTB in the northern part are lower than those in the southern part at $3.0 \mathrm{GHz}$, and the area with relatively lower nTB and ATB changes with frequency. The nTB and ATB in the northern part are similar to those in $\operatorname{Im} 2$, while the nTB and dTB in the southern part are similar to those in Im1 and Em1. This is another transition zone from the Ti-poor Im2 unit to Ti-rich Em1 unit. As shown by Figure 7, this unit has lower emissivity than Im2 but higher than Em4. Therefore, we maintain the unit distinction in the new map.

On the basis of the analysis described above, the mare basalt units in the CE-5 landing region have been combined into six units (IR, Im2, Im3, Em1, Em3, and Em4) and one hidden unit (IRh) using their thermophysical characteristics (Figure 12).

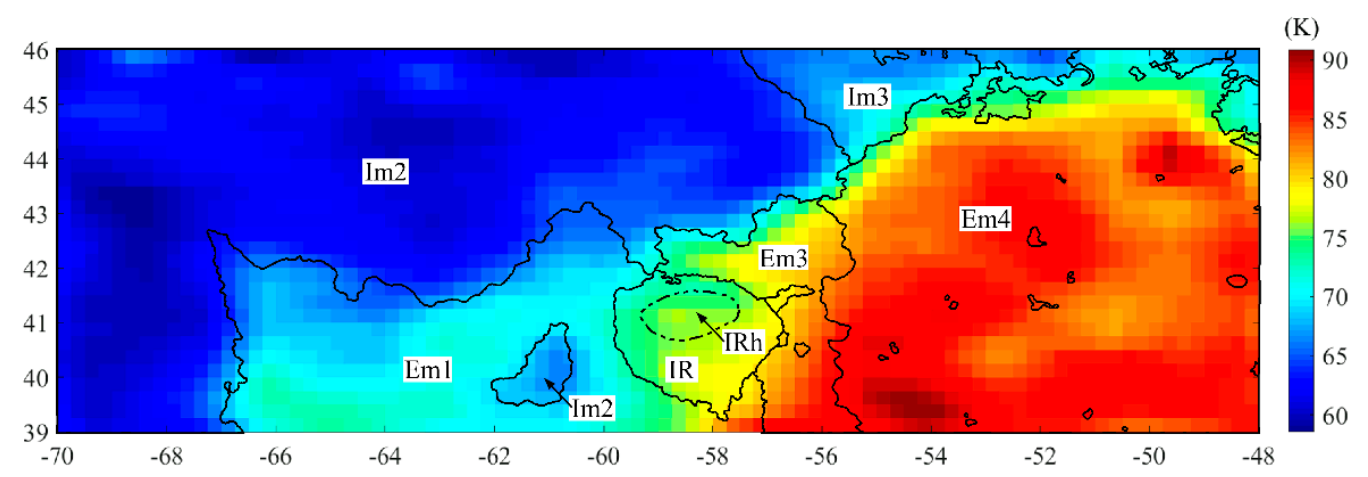

Figure 12. Geological units of the Rümker region. The basemap is the dTB at $37 \mathrm{GHz}$.

Therefore, the eruptive history of the Rümker region should be revisited. In previous studies, the correspondence between the age of the mare units and the $\mathrm{FeO}$ and $\mathrm{TiO}_{2}$ abundances is hard to understand $[14,16]$. Take the Eratosthenian-aged units for example, the mean noontime nTB 
is highest in Em4, followed by Em3, Em1, and Em2, and the mean nighttime nTB has an inverse sequence. These nTB performances agree well with the numerical simulation as shown in Figure 2 (Em1, Em2, Em3, and Em4 have 2.4, 1.6, 3.6, 6-7 wt. \% $\mathrm{TiO}_{2}$ abundances and similar FeO abundances). However, this also means that the $\mathrm{FeO}$ and $\mathrm{TiO}_{2}$ abundances of the Eratosthenian-aged mare basalts decrease from $\operatorname{Em} 1(2.30 \mathrm{Ga})$ to $\operatorname{Em} 2(2.13 \mathrm{Ga})$, and then increase from Em2 (2.13 Ga) to Em4 (1.21 Ga). If Em2 is combined into Im2, the evolution of the $\mathrm{FeO}$ and $\mathrm{TiO}_{2}$ in the Eratosthenian-aged Em1, Em3, and Em4 will follow the Ti enrichment trends (younger mare deposits will have the higher FeO and $\mathrm{TiO}_{2}$ abundances) confirmed by Staid et al. [60], Zhang et al. [61], and Haruyama et al. [62] . Similar phenomena also exist in the $\operatorname{Im} 1$, $\operatorname{Im} 2$, and $\operatorname{Im} 3$ units.

In summary, we present a revised geological history of the Rümker region on the basis of the thermophysical data. The Im 2 mare basalts are the oldest mare deposits ( 3.39 Ga), which is extensively distributed in the whole Rümker region, including the subsurface underlying Em4 in the east of the landing region [2]. This can be verified by the typical craters centered at $\left(53.0^{\circ} \mathrm{W}, 40.5^{\circ} \mathrm{N}\right)$ and $\left(51.0^{\circ} \mathrm{W}\right.$, $41.0^{\circ} \mathrm{N}$ ), where the mare deposit is interpreted as $\operatorname{Im} 2$ unit $[2,14,16]$. The volcanic activity of the $\operatorname{Im} 2$ era ended at about 3.39 Ga. Then, a smaller volume erupted at $\sim 3.16 \mathrm{Ga}$, forming the Im3 mare basalts in the north of the landing region. Thereafter, extensive mare eruptions occur in the Em1 ( 2.30 Ga), superposed on the Im2 unit in the southwest part of the Rümker region. Here, the Em2 unit mapped by Qian et al. [2] is likely the remanent of the Imbrian-aged Im 2 mare basalts when $\operatorname{Im} 1$ erupted and covered the region. Thereafter, basaltic volcanism was active in the eastern part of the Rümker region $(\sim 1.21 \mathrm{Ga})$ forming the mare basalts there. Here, all the absolute model ages of the mare units are those estimated by Qian et al. [2] using CSFD measurements.

Moreover, such basaltic volcanism also means that the $\mathrm{FeO}$ and $\mathrm{TiO}_{2}$ abundances become higher in the younger mare deposits, which is essentially important to further study the thermal evolution of the Moon.

\subsection{Scientifically Important Sampling Sites}

The Chang'e-5 (CE-5) mission is China's first lunar sample return mission, with a goal of returning samples from the Rümker region [4] (Figure 1). Detailed geological investigations of the area have been conducted recently by different researchers to assess its potential scientific value $[1,2,22,26,27,63-66]$. Within these analysis, 18 sampling sites or zones have been proposed and their scientific value evaluated [1,2,26,64,65,67] (Figure 13). The location and scientific value of the landing sites are summarized in Table 4.

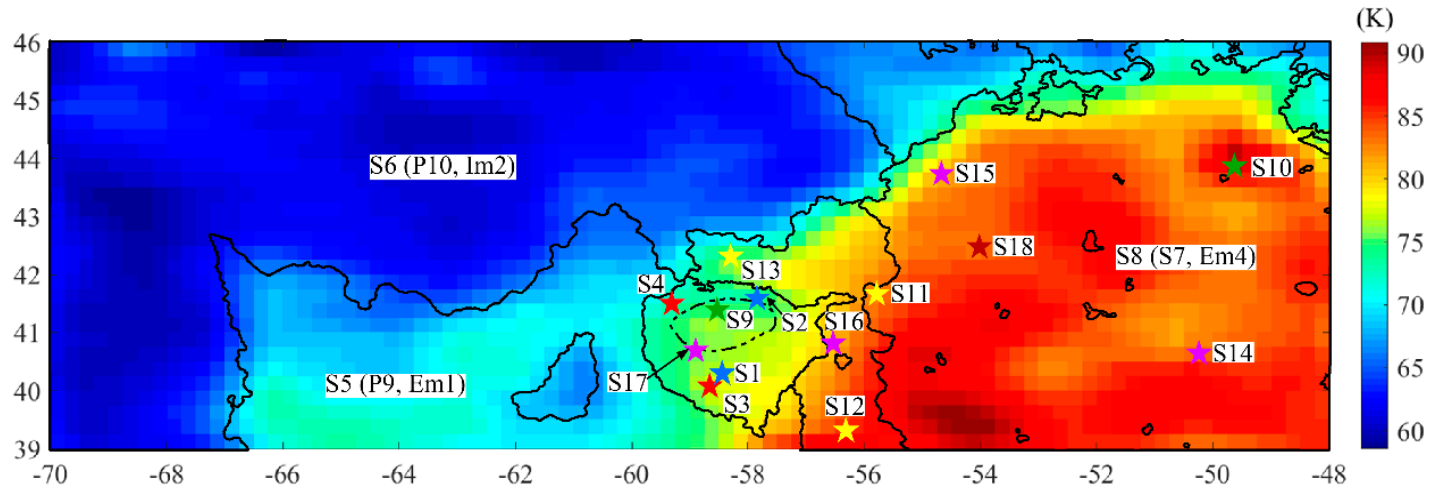

Figure 13. Proposed sampling sites in the Rümker region. The background is the dTB map at $37 \mathrm{GHz}$, the black lines outline the updated geological units combined on the basis of the CELMS data. Suggested sampling sites are marked by blue stars [67], red stars [1], green stars [2], yellow stars [65], purple stars [29], and brown stars [26]. Additionally, Site S5 was proposed by Ling et al. [63], and S8 was proposed by Ling et al. [63], Jolliff et al. [64], Qian et al. [2,27], and Xie et al. [26]. 
Table 4. Proposed sampling site in the Rümker region.

\begin{tabular}{|c|c|c|c|}
\hline Spots & Location & Unit & Scientific Value \\
\hline S1 & $\left(58.45^{\circ} \mathrm{W}, 40.33^{\circ} \mathrm{N}\right)^{\mathrm{Z} 1}$ & IR & $\begin{array}{l}\text { 1. Provide information on the formation of lunar domes } \\
\text { 2. Improve CSFD dating method }\end{array}$ \\
\hline S2 & $\left(57.85^{\circ} \mathrm{W}, 41.61^{\circ} \mathrm{N}\right)^{\mathrm{Z} 1}$ & IR & $\begin{array}{l}\text { 1. Help us analyze the evolutionary history of Mons Rümker } \\
\text { 2. Shed light on the age of some large impact events on the Moon }\end{array}$ \\
\hline S3 & $\left(58.66^{\circ} \mathrm{W}, 40.11^{\circ} \mathrm{N}\right) \mathrm{Z2}$ & IR & $\begin{array}{l}\text { 1. Study the origin of lunar domes } \\
\text { 2. Constrain the duration of Mons Rümker volcanism } \\
\text { 3. Improve CSFD dating method }\end{array}$ \\
\hline S4 & $\left(59.31^{\circ} \mathrm{W}, 41.52^{\circ} \mathrm{N}\right)^{\mathrm{Z} 2}$ & IR & $\begin{array}{l}\text { 1. Study the origin of lineated terrain } \\
\text { 2. Check if pyroclastic materials exist } \\
\text { 3. Determine the age of large impact events on the Moon } \\
\text { 4. Improve CSFD dating method }\end{array}$ \\
\hline S5 & $(\mathrm{P} 9)^{\mathrm{L}}$ & $\mathrm{Em} 1 / \operatorname{Im} 2$ & $\begin{array}{l}\text { 1. Help us evaluate the compositional properties of the young and } \\
\text { old basaltic units } \\
\text { 2. Be especially critical for evaluation of the lunar impact crater } \\
\text { statistics and planetary remotely sensed chronology }\end{array}$ \\
\hline S6 & $(\mathrm{P} 10)^{\mathrm{L}}$ & $\operatorname{Im} 2$ & $\begin{array}{l}\text { 1. Help us evaluate the compositional properties of the young and } \\
\text { old basaltic units } \\
\text { 2. Be especially critical for evaluation of the impact crater statistics } \\
\text { and planetary remotely sensed chronology }\end{array}$ \\
\hline S7 & $(\mathrm{P} 58)^{\mathrm{L}}$ & $\begin{array}{r}\mathrm{Em} 4 \\
/ \mathrm{Em} 3\end{array}$ & $\begin{array}{l}\text { 1. Help us evaluate the compositional properties of the young and } \\
\text { old basaltic units } \\
\text { 2. Be especially critical for evaluation of the lunar impact crater } \\
\text { statistics and planetary remotely sensed chronology } \\
\text { 3. Decipher some of the unresolved questions in late stage } \\
\text { volcanism on the Moon }\end{array}$ \\
\hline
\end{tabular}

1. Unsampled new rock type

2. Extent of lunar volcanism duration

3. Properties of late stage lunar volcanism

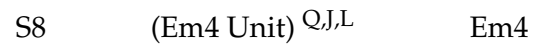

4. Deep mantle properties

5. Concentration mechanism of Th and its role in late stage volcanism

6. Precise isotopic age of young volcanism

7. Impact cratering flux history

8. Improving CSFD dating method and chronology

\begin{tabular}{|c|c|c|c|}
\hline S9 & $\left(58.53^{\circ} \mathrm{W}, 41.41^{\circ} \mathrm{N}\right) \mathrm{Q}$ & $\mathrm{IRh}$ & $\begin{array}{l}\text { 1. Origin of lunar domes } \\
\text { 2. Property of the magma source } \\
\text { 3. The duration of Mons Rümker volcanism } \\
\text { 4. Impact cratering flux history } \\
\text { 5. Improve CSFD dating method and chronology }\end{array}$ \\
\hline S10 & $\left(49.85^{\circ} \mathrm{W}, 43.68^{\circ} \mathrm{N}\right)^{\mathrm{Q}}$ & Em4 & $\begin{array}{l}\text { 1. Rock-type characteristic of the dome } \\
\text { 2. Origin of the silica-rich domes } \\
\text { 3. Properties of the magma source } \\
\text { 4. Evolution of magmas } \\
\text { 5. Influence of Th in silica dome formation } \\
\text { 6. The mechanism of Th concentration }\end{array}$ \\
\hline S11 & $\left(55.78^{\circ} \mathrm{W}, 41.69^{\circ} \mathrm{N}\right)^{\mathrm{G}}$ & Em4 & $\begin{array}{l}\text { 1. Provide measurements of trace element and major element } \\
\text { chemistry/mineralogy of various regolith components } \\
\text { 2. Fill in gaps in the lunar thermal evolution time scale } \\
\text { 3. Obtain most precise age determination } \\
\text { 4. The regolith consist of a complex mix of both local and distal } \\
\text { material via impact cratering }\end{array}$ \\
\hline S12 & $\left(56.31^{\circ} \mathrm{W}, 39.35^{\circ} \mathrm{N}\right)^{\mathrm{G}}$ & Em3 & $\begin{array}{l}\text { 1. Provide measurements of trace element and major element } \\
\text { chemistry/mineralogy of various regolith components } \\
\text { 2. Fill in gaps in the lunar thermal evolution time scale } \\
\text { 3. Obtain most precise age determination } \\
\text { 4. The regolith consist of a complex mix of both local and distal } \\
\text { material via impact cratering }\end{array}$ \\
\hline
\end{tabular}


Table 4. Cont.

\begin{tabular}{|c|c|c|c|}
\hline Spots & Location & Unit & Scientific Value \\
\hline S13 & $\left(58.3^{\circ} \mathrm{W}, 42.33^{\circ} \mathrm{N}\right)^{\mathrm{G}}$ & Em3 & $\begin{array}{l}\text { 1. Provide measurements of trace element and major element } \\
\text { chemistry/mineralogy of various regolith components } \\
\text { 2. Fill in gaps in the lunar thermal evolution time scale } \\
\text { 3. Obtain most precise age determination } \\
\text { 4. The regolith consists of a complex mix of both local and distal } \\
\text { material via impact cratering } \\
\text { 5. Provides for greater availability of helium-3 }\end{array}$ \\
\hline S14 & $\left(50.24^{\circ} \mathrm{W}, 40.67^{\circ} \mathrm{N}\right)^{\mathrm{C}}$ & Em4 & $\begin{array}{l}\text { 1. A possible conduit for transportation of youngest basaltic } \\
\text { magma/lavas with high Fe and Ti from the mantle to the surface } \\
\text { 2. A higher chance of sampling lava flows derived from the mantle } \\
\text { different from other young basaltic surface materials }\end{array}$ \\
\hline S15 & $\left(54.67^{\circ} \mathrm{W}, 43.75^{\circ} \mathrm{N}\right)^{\mathrm{C}}$ & Em4 & $\begin{array}{l}\text { 1. Increase the possibility of collecting samples of materials } \\
\text { representing a long time span } \\
\text { 2. The landing site features an unusual structure on the } \\
\text { derivative maps }\end{array}$ \\
\hline S16 & $\left(56.53^{\circ} \mathrm{W}, 40.84^{\circ} \mathrm{N}\right)^{\mathrm{C}}$ & Em3 & $\begin{array}{l}\text { 1. Provide information on the early Eratosthenian volcanism } \\
\text { 2. Provide knowledge on the differences in composition, mode of } \\
\text { emplacement of the Imbrian and widespread volcanism } \\
\text { 3. Provide knowledge that leads to the formation of the Imbrian } \\
\text { and widespread volcanism }\end{array}$ \\
\hline S17 & $\left(58.9^{\circ} \mathrm{W}, 40.72^{\circ} \mathrm{N}\right)^{\mathrm{C}}$ & IR & $\begin{array}{l}\text { 1. Provide information on the Imbrian/Eratosthenian transition } \\
\text { 2. Provide potential samples of the Rümker complex } \\
\text { uncontaminated by the mare deposits }\end{array}$ \\
\hline S18 & $\left(53.94^{\circ} \mathrm{W}, 42.46^{\circ} \mathrm{N}\right)^{\mathrm{X}}$ & Em4 & $\begin{array}{l}\text { 1. The areas are covered by a thin-layer ejecta from nearby craters, } \\
\text { in which a deeper drill has a higher possibility sampling older and } \\
\text { more DSPs. } \\
\text { 2. The core samples may contain basaltic materials from Em4, Im1, } \\
\text { Im2, and Im3. }\end{array}$ \\
\hline
\end{tabular}

Note: the alphabet ${ }^{\mathrm{Z1}}$ is Zhao et al. [67], ${ }^{\mathrm{Z} 2}$ is Zhao et al. [1], ${ }^{\mathrm{L}}$ is Ling et al. [63], ${ }^{\mathrm{Q}}$ is Qian et al. [2], ${ }^{\mathrm{J}}$ is Jolliff et al. [64], ${ }^{G}$ is Giguere et al. [65], ${ }^{C}$ is Chisenga et al. [29], and ${ }^{\mathrm{X}}$ is Xie et al. [26].

In summary, the 18 sampling sites are proposed to answer the four following scientific questions.

(1) The samples from the young mare basalt (Em4) would provide new knowledges of (1) the geochemistry and mineralogy of its mantle source regions, (2) how the radioactive elements in Procellarum KREEP Terrane affects the generation of late-stage mare volcanism, (3) the late stage thermal evolution of the lunar interior, and (4) the impact chronology history of the Moon and the inner planets. Therefore, Em4 is always ranked as the first-priority sampling unit. Seven of the eighteen proposed landing sites are in Em4. Jolliff et al. [64], Ling et al. [63], and Qian et al. [2,27] suggested that sampling anywhere in the Em4 unit could return young mare materials and fulfill the desired scientific goals (Sites S7 and S8 in Table 4 and Figure 10), while Sites S10, S11, S14, S15, and S18 are provided by Ling et al. [63], Qian et al. [2], Giguere et al. [65], Chisenga et al. [29], and Xie et al. [26], respectively.

As shown by the dTB map at $37 \mathrm{GHz}$ in Figure 13, the characteristics of the youngest mare deposit in Em4 are not homogeneous. Sites S11 and S15, located near the boundary of Em4, are homogeneous in the vertical direction according to the four-channel nTB and dTB maps. Sites S11 and S18 are located in a site with abnormally higher $\mathrm{FeO}$ and $\mathrm{TiO}_{2}$ abundances compared to the remaining areas in Em4. Site S14 is in a place with relatively thinner Em4 mare deposits, where the nTB and dTB maps indicate a distinctly different thermal behavior compared to its surroundings in Em4. The TB performances in Site S10 are interesting, and show the nearly highest noon nTB at 3.0 and $7.8 \mathrm{GHz}$, almost the lowest night nTB at 7.8, 19.35, and $37 \mathrm{GHz}$, and the highest dTB. Such TB behaviors are usually caused by high $\mathrm{FeO}$ and $\mathrm{TiO}_{2}$ abundances, but not supported by the compositional measurements in Figure 8, indicating that this is a special hidden structure. 
(2) Mons Rümker is ranked as the second priority landing site, and six of the proposed eighteen landing sites are located in the unit, mainly proposed by Zhao et al. [1] and Qian et al. [2]. Generally, Sites S1, S2, S3, S4, and S17 are located in the new IR unit, while Site S9 is in the IRh unit which is thought to be a special hidden construct in this study. Due to the resolution limitation of the CELMS data, it is impossible to obtain the thermophysical properties of the proposed domes recommended by Zhao et al. [1].

(3) Em3 is ranked as the third priority landing site, which is mainly proposed by Ling et al. [63] and Giguere et al. [19], including Sites S12, S13, and S16. As mentioned in Sections 4.2 and 5.1, the three sites are located in the transitional areas between the Ti-rich mare unit to the Ti-poor unit. Moreover, the nTB and dTB maps show that Site S12 likely belongs to Em4 at depth, while the regolith thermophysical features change greatly in Sites S13 and S16.

(4) Sites S5 (Em1 unit, referred to P9 unit by Hiesinger et al. [14]) and S6 (Im2 unit, referred to P10 unit by Hiesinger et al. [14]) are proposed by Ling et al. [63], and are located in the west part of the Rümker region.

Generally, according to the thermophysical features and their scientific potentials of the mare units, we proposed the following sites as the sampling candidates. Two sites are of judged to be of equal importance from the thermophyscial and scientific goals point of view (Table 4).

The first of these two highest priority sites is given to the Em4 unit proposed by Qian et al. [2], Giguere et al. [65], Chisenga et al. [29], and Xie et al. [26]. Here, Site S14 should be ranked as first, for it exists in a belt with relatively lower noon nTB and dTB values compared to the other place in Em4. The low-dTB belt indicates a strong correlation with Rima Sharp as shown in Figure 6d. Rima Sharp may be one of the magma sources of the Em4 mare basalts, which is currently under check by Qian et al. [27]. Besides, the density anomaly in this site was proposed as potential magma sources by Chisenga et al. [29]. Besides the scientific values mentioned in Table 4, the sampling study will give additional fundamental information about the basaltic evolution in the late stage of the Moon. Site S10 should be ranked as second in Em4, with the highest nTB at noon and the lowest nTB, indicating that there exists a hidden structure. Therefore, besides the scientific values mentioned by Qian et al. [2], the sampling deposits will indicate abundant information about the mare deposits covered by the impact ejecta. Therefore, the returned sample will provide opportunities to study the young mare basalts and the covered old basalts.

The second of these two highest priority sites is the Em1 unit, including Em1 and Im1 subdivided by Qian et al. [2]. The Rümker region has been thoroughly studied with multiple sources of optical data. The results all indicate that Em4 is the youngest mare unit and $\operatorname{Im} 2$ is almost the oldest mare deposit in this region. However, the ages of $\operatorname{Im} 1$ and Em1 are in debate. Hiesinger et al. [14] suggested an age of $3.47 \mathrm{Ga}$ for the unit, while Qian et al. [2] proposed the age of $3.42 \mathrm{Ga}$ for $\operatorname{Im} 1$ in the west and 2.30 for Em1 in the east. Moreover, there is a small region named Em2 by Qian et al. [2], which is not identified by Hiesinger et al. [14] but re-interpreted as $\operatorname{Im} 2$ according to the nTB and dTB characteristics. Therefore, we propose a landing site centered at $\left(61^{\circ} \mathrm{W}, 41^{\circ} \mathrm{N}\right)$. Besides the scientific values mentioned by Ling et al. [63] and Giguere et al. [19], the sampling in this place will provide additional information about 1) to identify the ages of Im1, Em1, and Em2 interpreted by Qian et al. [27] and Hiesinger et al. [14], 2) to identify the relationship between Em1, Em2, Im1, and Im2 and then re-understand the basaltic volcanism in the Rümker region. The change of the $\mathrm{FeO}$ and $\mathrm{TiO}_{2}$ abundances with the age is a critical problem to study the thermal evolution of the Moon. However, the irregular change of the $\mathrm{FeO}$ and $\mathrm{TiO}_{2}$ abundances with age may be related to the existence of overturn in the lunar mantle. If the ages of the Em1, Em2, Im1, and $\operatorname{Im} 2$ can be accurately acquired through CE-5 sampling, a new view about the thermal evolution will be provided. Additionally, according to the studies by Xie et al. [26], there will exist the impact ejecta from IR, Im1, Em3, and Em4 units, which can fulfill the scientific values in Em4 proposed by other researchers.

The second priority is given to Site S9 in the northern part of Mons Rümker. The nTB and dTB characteristics show that the mare deposits in Mons Rümker are different from the nearby units. 
Besides the scientific goals mentioned by Zhao et al. [1,67], Qian et al. [2], and Chisenga et al. [29], the sampling in this location could help resolve the nature and origin of the hidden construct and the thermophysically similar distinctive mare deposits also found in Mare Moscoviense, Mare Nubium, and the Apollo basin $[30,33,51]$.

\section{Conclusions}

In this study, the CELMS data from the CE-2 spacecraft is employed to study the thermophysical characteristics, properties, and distinctive features of the Rümker region. The main results are as follows.

(1) In this analysis, we generated and combined (a) the TB, nTB, and dTB maps derived from the CE-2 CELMS data; (b) the emissivity maps derived by using LRO Diviner data, and (c) the simulated surface temperatures generated. On the basis of these data, the thermophysical properties of the previously mapped geological units are evaluated.

(2) According to the nTB and ATB behavior and the emissivity features, the ten mare units interpreted by Qian et al. [27] can be reclassified into 7 units including a hidden construct named IRh on Mons Rümker.

(3) The $18 \mathrm{CE}-5$ candidate sampling sites proposed by previous researchers are evaluated using the nTB, dTB, and emissivity performances. Finally, on the basis of their thermophysical properties, four candidate landing sites are suggested for the CE- 5 mission. Both the Em 4 and Em 1 units would potentially provide the highest scientific return, followed by the IRh unit.

Author Contributions: Conceptualization, Z.M.; methodology, Z.M. and Y.Q.; software, J.L. and W.C.; validation, L.X. and J.W.H.; formal analysis, Z.M. and J.S.; investigation, Z.M. and J.P.; resources, Z.M. and S.C.; data curation, J.S. and J.L.; writing original draft preparation, Z.M.; writing review and editing, Y.Q., L.X., and J.W.H.; visualization, Z.M. and J.P.; supervision, S.C. and Z.K.; project administration, Z.M.; funding acquisition, S.C. and W.C. All authors have read and agreed to the published version of the manuscript.

Funding: This work was supported by the B-type Strategic Priority Research Program of Chinese Academy of Sciences (No. XDB41000000), the National Natural Science Foundation of China (No. 42071309, 41772346, 41372337, 41802246), a grant from State Key Laboratory of Resources and Environmental Information System, and the National Key R \& D Program of China (No. 2016YFC0600501).

Acknowledgments: The authors express their thanks to the people helping with this work, and acknowledge the valuable suggestions from the peer reviewers. In this study, the CELMS data were downloaded from http://moon.bao.ac.cn/, the Kaguya MI data were downloaded from http://darts.isas.jaxa.jp/planet/pdap/selene/. We are grateful for allowing us to use their data.

Conflicts of Interest: The authors declare no conflict of interest regarding the publication of this paper.

\section{References}

1. Zhao, J.; Xiao, L.; Qiao, L.; Glotch, T.D.; Huang, Q. The Mons Rümker volcanic complex of the Moon: A candidate landing site for the Chang'E-5 mission. J. Geophys. Res. Planets 2017, 122, 1419-1442. [CrossRef]

2. Qian, Y.Q.; Xiao, L.; Zhao, S.Y.; Zhao, J.; Huang, J.; Flahaut, J.; Martinot, M.; Head, J.W.; Hiesinger, H.; Wang, G.X. Geology and Scientific Significance of the Rümker Region in Northern Oceanus Procellarum: China's Chang'E-5 Landing Region. J. Geophys. Res. Planets 2018, 123, 1407-1430. [CrossRef]

3. Pei, Z.; Wang, Q.; Tian, Y. Technology roadmap for Chang'E Program. J. Deep Space Explor. 2015, 2, 99-110.

4. Li, C.; Wang, C.; Wei, Y.; Lin, Y. China's present and future lunar exploration program. Science 2019, 365, 238-239. [CrossRef]

5. Jolliff, B.L.; Gillis, J.J.; Haskin, L.A.; Korotev, R.L.; Wieczorek, M.A. Major lunar crustal terranes: Surface expressions and crust-mantle origins. J. Geophys. Res. Space Phys. 2000, 105, 4197-4216. [CrossRef]

6. Kring, D.A.; Durda, D. A Global Lunar Landing Site Study to Provide the Scientific Context for Exploration of the Moon; Lunar and Planetary Institute: Houston, TX, USA, 2012. 
7. Committee on the Scientific Context for Exploration of the Moon; Board, S.S. Division on Engineering and Physical Sciences; National Research Council the Scientific Context for Exploration of the Moon. In The Scientific Context for Exploration of the Moon; The National Academies Press: Washington, DC, USA, 2007. [CrossRef]

8. Prettyman, T.H.; Hagerty, J.J.; Elphic, R.C.; Feldman, W.C.; Lawrence, D.J.; McKinney, G.W.; Vaniman, D.T. Elemental composition of the lunar surface: Analysis of gamma ray spectroscopy data from Lunar Prospector. J. Geophys. Res. Space Phys. 2006, 111. [CrossRef]

9. Wieczorek, M.A.; Neumann, G.A.; Nimmo, F.; Kiefer, W.S.; Taylor, G.J.; Melosh, H.J.; Phillips, R.J.; Solomon, S.C.; Andrews-Hanna, J.C.; Asmar, S.W.; et al. The Crust of the Moon as Seen by GRAIL. Science 2012, 339, 671-675. [CrossRef]

10. Head, J.W.; Wilson, L. Generation, ascent and eruption of magma on the Moon: New insights into source depths, magma supply, intrusions and effusive/explosive eruptions (Part 2: Predicted emplacement processes and observations). Icarus 2017, 283, 176-223. [CrossRef]

11. Wilson, L.; Head, J.W. Generation, ascent and eruption of magma on the Moon: New insights into source depths, magma supply, intrusions and effusive/explosive eruptions (Part 1: Theory). Icarus 2017, 283, 146-175. [CrossRef]

12. Wieczorek, M.A.; Phillips, R.J. The "Procellarum KREEP Terrane": Implications for mare volcanism and lunar evolution. J. Geophys. Res. Planets 2000, 105, 20417-20430. [CrossRef]

13. Ziethe, R.; Seiferlin, K.; Hiesinger, H. Duration and extent of lunar volcanism: Comparison of 3D convection models to mare basalt ages. Planet. Space Sci. 2009, 57, 784-796. [CrossRef]

14. Hiesinger, H.; Head, J.; Wolf, U.; Jaumann, R.; Neukum, G. Ages and stratigraphy of lunar mare basalts: A synthesis. Recent Adv. Curr. Res. Issues Lunar Stratigr. 2011, 477, 1-51.

15. Morota, T.; Haruyama, J.; Ohtake, M.; Matsunaga, T.; Honda, C.; Yokota, Y.; Kimura, J.; Ogawa, Y.; Hirata, N.; Demura, $\mathrm{H}_{\text {; }}$ et al. Timing and characteristics of the latest mare eruption on the Moon. Earth Planet. Sci. Lett. 2011, 302, 255-266. [CrossRef]

16. Hiesinger, H.; Head, J.W.; Wolf, U.; Jaumann, R.; Neukum, G. Ages and stratigraphy of mare basalts in Oceanus Procellarum, Mare Nubium, Mare Cognitum, and Mare Insularum. J. Geophys. Res. Planets 2003, 108. [CrossRef]

17. Glotch, T.D.; Hagerty, J.J.; Lucey, P.; Hawke, B.R.; Giguere, T.A.; Arnold, J.A.; Williams, J.-P.; Jolliff, B.L.; Paige, D.A. The Mairan domes: Silicic volcanic constructs on the Moon. Geophys. Res. Lett. 2011, 38. [CrossRef]

18. Hurwitz, D.M.; Head, J.W.; Wilson, L.; Hiesinger, H. Origin of lunar sinuous rilles: Modeling effects of gravity, surface slope, and lava composition on erosion rates during the formation of Rima Prinz. J. Geophys. Res. Planets 2012, 117. [CrossRef]

19. Giguere, T.; Boyce, J.; Gillis-Davis, J.; Stopar, J. Lava Flows in Northeastern Oceanus Procellarum: Morphology, Composition, and Ages. In Proceedings of the 51st Lunar and Planetary Science Conference, Woodlands, TX, USA, 16-20 March 2020. Abstract 2356.

20. Jia, M.; Yue, Z.; Di, K.; Liu, B.; Liu, J.; Michael, G. A catalogue of impact craters larger than $200 \mathrm{~m}$ and surface age analysis in the Chang'e-5 landing area. Earth Planet. Sci. Lett. 2020, 541. [CrossRef]

21. Qian, Y.; Xiao, L.; Head, J. The Young Mare Basalts in Chang'E 5 Mission Landing Region, Northern Oceanus Procellarum. In Proceedings of the 51st Lunar and Planetary Science Conference, Woodlands, TX, USA, 16-20 March 2020. Abstract 1459.

22. Wu, B.; Huang, J.; Li, Y.; Wang, Y.; Peng, J. Rock Abundance and Crater Density in the Candidate Chang'E-5 Landing Region on the Moon. J. Geophys. Res. Planets 2018, 123, 3256-3272. [CrossRef]

23. Boroughs, L.L.; Spudis, P.D. The stratigraphy of lava flows in northern Oceanus Procellarum, Moon. In Proceedings of the 32nd Annual Lunar and Planetary Science Conference, Houston, TX, USA, 12-16 March 2001. Abstract 1192.

24. Zhang, G.; Li, C.; Liu, D.; Liu, B.; Zhou, Q.; Gao, F.; Zhang, H.; Kong, D.; Ren, X. Storage, Processing, and Preparation Methods for China's Returned Lunar Samples. In Proceedings of the 51st Lunar and Planetary Science Conference, Woodlands, TX, USA, 16-20 March 2020. Abstract 1394.

25. Campbell, B.A.; Hawke, B.R.; Campbell, D.B. Surface morphology of domes in the Marius Hills and Mons Rümker regions of the Moon from Earth-based radar data. J. Geophys. Res. Planets 2009, 114. [CrossRef] 
26. Xie, M.; Xiao, Z.; Zhang, X.; Xu, A.-A. The Provenance of Regolith at the Chang'e-5 Candidate Landing Region. J. Geophys. Res. Planets 2020, 125. [CrossRef]

27. Qian, Y.; Xiao, L.; Yin, S.; Zhang, M.; Zhao, S.; Pang, Y.; Wang, J.; Wang, G.; Head, J.W. The regolith properties of the Chang'e-5 landing region and the ground drilling experiments using lunar regolith simulants. Icarus 2020, 337. [CrossRef]

28. Yue, Z.; Di, K.; Liu, Z.; Michael, G.; Jia, M.; Xin, X.; Liu, B.; Peng, M.; Liu, J. Lunar regolith thickness deduced from concentric craters in the CE-5 landing area. Icarus 2019, 329, 46-54. [CrossRef]

29. Chisenga, C.; Yan, J.; Zhao, J.; Atekwana, E.A.; Steffen, R. Density Structure of the Rümker Region in the Northern Oceanus Procellarum: Implications for Lunar Volcanism and Landing Site Selection for the Chang'E-5 Mission. J. Geophys. Res. Planets 2020, 125. [CrossRef]

30. Meng, Z.; Chen, S.; Wang, Y.; Wang, T.; Cai, Z.; Zhang, Y.; Zheng, Y.-C.; Hu, S. Reevaluating Mare Moscoviense And Its Vicinity Using Chang'e-2 Microwave Sounder Data. Remote. Sens. 2020, 12, 535. [CrossRef]

31. Campbell, B.A.; Carter, L.M.; Hawke, B.R.; Campbell, D.B.; Ghent, R.R. Volcanic and impact deposits of the Moon's Aristarchus Plateau: A new view from Earth-based radar images. Geology 2008, 36, 135-138. [CrossRef]

32. Meng, Z.; Hu, S.; Wang, T.; Li, C.; Cai, Z.; Ping, J. Passive Microwave Probing Mare Basalts in Mare Imbrium Using CE-2 CELMS Data. IEEE J. Sel. Top. Appl. Earth Obs. Remote. Sens. 2018, 11, 3097-3104. [CrossRef]

33. Meng, Z.; Wang, Y.; Chen, S.; Zheng, Y.-C.; Shi, J.; Wang, T.; Zhang, Y.; Ping, J.; Hou, L. MTE Features of Apollo Basin and Its Significance in Understanding the SPA Basin. IEEE J. Sel. Top. Appl. Earth Obs. Remote. Sens. 2019, 12, 2575-2583. [CrossRef]

34. Liu, C.; Sun, H.-Y.; Meng, Z.-G.; Zheng, Y.-C.; Lu, Y.; Cai, Z.-C.; Ping, J.-S.; Gusev, A.; Hu, S. Retrieving volume $\mathrm{FeO}$ and $\mathrm{TiO}_{2}$ abundances of lunar regolith with CE-2 CELMS data using BPNN method. Res. Astron. Astrophys. 2019, 19, 066. [CrossRef]

35. Zheng, Y.-C.; Chan, K.L.; Tsang, K.T.; Zhu, Y.-C.; Hu, G.P.; Blewett, D.T.; Neish, C. Analysis of Chang'E-2 brightness temperature data and production of high spatial resolution microwave maps of the Moon. Icarus 2019, 319, 627-644. [CrossRef]

36. Hagfors, T. Microwave Studies of Thermal Emission from the Moon. In Advances in Astronomy and Astrophysics; Elsevier BV: Amsterdam, The Netherlands, 1971; Volume 8, pp. 1-28.

37. Keihm, S.J. Effects of subsurface volume scattering on the lunar microwave brightness temperature spectrum. Icarus 1982, 52, 570-584. [CrossRef]

38. Keihm, S.J. Interpretation of the lunar microwave brightness temperature spectrum: Feasibility of orbital heat flow mapping. Icarus 1984, 60, 568-589. [CrossRef]

39. Jin, Y.; Yan, F.; Liang, Z. Simulation for remote sensing of the lunar soil and rock by using multi-channels microwave radiometers. Chin. J. Radio Sci. 2003, 18, 477-486.

40. Wang, Z.; Li, Y.; Jiang, J.; Li, D. Lunar surface dielectric constant, regolith thickness, and 3He abundance distributions retrieved from the microwave brightness temperatures of CE-1 Lunar Microwave Sounder. Sci. China Earth Sci. 2010, 53, 1365-1378. [CrossRef]

41. Meng, Z.; Zhang, J.; Cai, Z.; Ping, J.; Tang, Z.-S. Microwave Thermal Emission Features of Mare Orientale Revealed by CELMS Data. IEEE J. Sel. Top. Appl. Earth Obs. Remote. Sens. 2017, 10, 2991-2998. [CrossRef]

42. Meng, Z.; Yang, G.; Ping, J.; Cai, Z.; Gusev, A.; Osei, E.M. Influence of (FeO+TiO2) abundance on the microwave thermal emissions of lunar regolith. Sci. China Earth Sci. 2016, 59, 1498-1507. [CrossRef]

43. Heiken, G.H.; Vaniman, D.T.; French, B.M. Lunar Sourcebook, a User's Guide to the Moon; Cambridge University Press: Cambridge, UK, 1991.

44. Meng, Z.; Wang, Q.; Wang, H.; Wang, T.; Cai, Z. Potential Geologic Significances of Hertzsprung Basin Revealed by CE-2 CELMS Data. IEEE J. Sel. Top. Appl. Earth Obs. Remote. Sens. 2018, 11, 3713-3720. [CrossRef]

45. Williams, J.-P.; Paige, D.; Greenhagen, B.T.; Sefton-Nash, E. The global surface temperatures of the Moon as measured by the Diviner Lunar Radiometer Experiment. Icarus 2017, 283, 300-325. [CrossRef]

46. Zhiguo, M.; Yi, X.; Zhanchuan, C.; Shengbo, C.; Yi, L.; Hang, H. Influence of lunar topography on simulated surface temperature. Adv. Space Res. 2014, 54, 2131-2139. [CrossRef] 
47. Otake, H.; Ohtake, M.; Hirata, N. Lunar iron and titanium abundance algorithms based on SELENE (Kaguya) Multiband Imager data. In Proceedings of the 43rd Lunar and Planetary Science Conference, Woodlands, TX, USA, 19-23 March 2012. Abstract 1905.

48. Cai, Z.; Lan, T. Lunar Brightness Temperature Model Based on the Microwave Radiometer Data of Chang'e-2. IEEE Trans. Geosci. Remote. Sens. 2017, 55, 5944-5955. [CrossRef]

49. Zheng, Y.-C.; Tsang, K.; Chan, K.; Zou, Y.; Zhang, F.; Ouyang, Z.; Zheng, Y.-C. First microwave map of the Moon with Chang'E-1 data: The role of local time in global imaging. Icarus 2012, 219, 194-210. [CrossRef]

50. Chan, K.L.; Tsang, K.T.; Kong, B.; Zheng, Y.-C. Lunar regolith thermal behavior revealed by Chang'E-doi:10.1109/tgrs.2017.27180271 microwave brightness temperature data. Earth Planet. Sci. Lett. 2010, 295, 287-291. [CrossRef]

51. Meng, Z.; Chen, S.; Zheng, Y.; Cheng, W.; Zhu, Y.; Cai, Z.; Zhang, Y.; Cao, W.; Hou, L. Mare Deposits Identification and Feature Analysis in Mare Australe Based On CE-2 CELMS Data. J. Geophys. Res. Planets 2020. [CrossRef]

52. Hu, G.-P.; Chan, K.L.; Zheng, Y.-C.; Xu, A.-A. A Rock Model for the Cold and Hot Spots in the Chang'E Microwave Brightness Temperature Map. IEEE Trans. Geosci. Remote. Sens. 2018, 56, 5471-5480. [CrossRef]

53. Meng, Z.; Wang, H.H.; Zheng, Y.-C.; Wang, Y.; Miyamoto, H.; Cai, Z.C.; Ping, J.S.; Zhu, Y.Z. Several Geological Issues of Schrödinger Basin Exposed by CE-2 CELMS Data. Adv. Astron. 2019, 2019, 3926082. [CrossRef]

54. Jiang, J.; Wang, Z.; Zhang, X.; Zhang, D.; Li, Y.; Lei, L.; Zhang, W.; Cui, H.; Guo, W.; Li, D. China probe CE-1 unveils world first moon-globe microwave emission map: The microwave moon some exploration results of Chang'E-1 microwave sounder. Remote Sens. Technol. Appl. 2009, 24, 409-422.

55. Zhu, Y.; Zheng, Y.; Fang, S.; Zou, Y.; Pearson, S. Analysis of the brightness temperature features of the lunar surface using $37 \mathrm{GHz}$ channel data from the Chang'E-2 microwave radiometer. Adv. Space Res. 2019, 63, 750-765. [CrossRef]

56. Meng, Z.; Chen, S.; Wang, Y.; Cheng, W.; Jin, S.; Cai, Z.; Hu, S. Complex Mare Deposits Revealed by CE-2 CELMS Data in Mare Nubium. IEEE J. Sel. Top. Appl. Earth Obs. Remote. Sens. 2020, 13, 2475-2484. [CrossRef]

57. Stöffler, D.; Ryder, G. Stratigraphy and Isotope Ages of Lunar Geologic Units: Chronological Standard for the Inner Solar System. Space Sci. Rev. 2001, 96, 9-54. [CrossRef]

58. Hao, W.; Zhu, C.; Li, F.; Yan, J.; Ye, M.; Barriot, J.-P. Illumination and communication conditions at the Mons Rümker region based on the improved Lunar Orbiter Laser Altimeter data. Planet. Space Sci. 2019, 168, 73-82. [CrossRef]

59. Zhong, Z.; Yan, J.; Xiao, Z. Lunar Regolith Temperature Variation in the Rümker Region Based on the Real-Time Illumination. Remote. Sens. 2020, 12, 731. [CrossRef]

60. Staid, M.I.; Pieters, C.M.; Besse, S.; Boardman, J.; Dhingra, D.; Green, R.; Head, J.W.; Isaacson, P.; Klima, R.; Kramer, G.; et al. The mineralogy of late stage lunar volcanism as observed by the Moon Mineralogy Mapper on Chandrayaan-1. J. Geophys. Res. Planets 2011, 116. [CrossRef]

61. Zhang, X.-Y.; Ouyang, Z.-Y.; Zhang, X.-M.; Chen, Y.; Tang, X.; Xu, A.-A.; Tang, Z.-S.; Wu, Y. Study of the continuum removal method for the Moon Mineralogy Mapper (M3) and its application to Mare Humorum and Mare Nubium. Res. Astron. Astrophys. 2016, 16, 115. [CrossRef]

62. Ohtake, M.; Matsunaga, T.; Haruyama, J.; Yokota, Y.; Morota, T.; Honda, C.; Ogawa, Y.; Torii, M.; Miyamoto, H.; Arai, T.; et al. The global distribution of pure anorthosite on the Moon. Nature 2009, 461, 236-240. [CrossRef] [PubMed]

63. Ling, Z.; Liu, C.; Jolliff, B.; Zhang, J.; Li, B.; Sun, L.; Chen, J.; Liu, J. Spectral and Mineralogical Analysis of Chang'e-5 Candidate Landing Site in Northern Oceanus Procellarum. In Proceedings of the 48th Lunar and Planetary Science Conference, Woodlands, TX, USA, 20-24 March 2017. Abstract 2079.

64. Jolliff, B.; Wang, A.; Ling, Z.; Zhang, J. Scientific context and objectives for Chang'E-4 and Chang'E-5 missions. In Proceedings of the 3rd Beijing International Forum on Lunar and Deep-Space Exploration, Beijing, China, 19-22 September 2017.

65. Giguere, T.; Gillis-Davis, J.; Trang, D.; Jolliff, B. Analysis of the Rumker Hills Region: Chang'e 5 Landing Site Assessment. In Proceedings of the 49th Lunar and Planetary Science Conference, Woodlands, TX, USA, 19-23 March 2018. Abstract 2844. 
66. Michael, G.; Yue, Z.; Gou, S.; Di, K. Dating Individual Several-km Lunar Impact Craters from the Rim Annulus in Region of Planned Chang'E-5 Landing. In Proceedings of the 50th Lunar and Planetary Science Conference, Woodlands, TX, USA, 18-22 March 2019. Abstract 2837.

67. Zhao, J.; Xiao, L.; Qiao, L. The Mons Rümker Volcanic Complex of the Moon: A Candidate Landing Site for Chang'e-5 Mission. In Proceedings of the 47th Lunar and Planetary Science Conference, Woodlands, TX, USA, 21-25 March 2016. Abstract 1758.

(C) 2020 by the authors. Licensee MDPI, Basel, Switzerland. This article is an open access article distributed under the terms and conditions of the Creative Commons Attribution (CC BY) license (http://creativecommons.org/licenses/by/4.0/). 